\title{
Energy Efficiency of Hydrogen Sulfide Decomposition in a Pulsed Corona Discharge Reactor
}

\author{
Morris D. Argyle \\ mdargyle@byu.edu \\ Sanil John \\ Jerry C. Hamann \\ Suresh S. Muknahallipatna \\ Stanislaw Legowski \\ Eellony this and fadditionahworkstatithttps://scholarsarchive.byu.edu/facpub \\ Part of the Chemical Engineering Commons
}

\section{Original Publication Citation}

S. John, J.S. Hamann, S. Muknahallipatna, S. Legowski, J.F. Ackerman, M.D. Argyle, "Energy efficiency of hydrogen sulfide decomposition in a pulsed corona discharge reactor." Chemical Engineering Science, 64, 4826-4834, 29. http://www.sciencedirect.com/science/journal/9259/ $64 / 23$

\section{BYU ScholarsArchive Citation}

Argyle, Morris D.; John, Sanil; Hamann, Jerry C.; Muknahallipatna, Suresh S.; Legowski, Stanislaw; and Ackerman, John F., "Energy Efficiency of Hydrogen Sulfide Decomposition in a Pulsed Corona Discharge Reactor" (2009). Faculty Publications. 115. https://scholarsarchive.byu.edu/facpub/115

This Peer-Reviewed Article is brought to you for free and open access by BYU ScholarsArchive. It has been accepted for inclusion in Faculty Publications by an authorized administrator of BYU ScholarsArchive. For more information, please contact ellen_amatangelo@byu.edu. 


\section{Authors}

Morris D. Argyle, Sanil John, Jerry C. Hamann, Suresh S. Muknahallipatna, Stanislaw Legowski, and John F. Ackerman 


\title{
Energy Efficiency of Hydrogen Sulfide Decomposition in a Pulsed Corona Discharge Reactor
}

Sanil John, ${ }^{1}$ Jerry C. Hamann, ${ }^{2}$ Suresh S. Muknahallipatna, ${ }^{2}$ Stanislaw Legowski, ${ }^{2}$ John F. Ackerman ${ }^{1}$, and Morris D. Argyle ${ }^{1 *}$

(1) Department of Chemical \& Petroleum Engineering, (2) Department of Electrical \& Computer Engineering, University of Wyoming, 1000 E. University Avenue, Laramie, WY 82071

\begin{abstract}
A novel pulsed corona wire-in-tube reactor with quartz view-ports allowed visual observation of the effect of charge voltage and gas composition on the corona distribution. The $\mathrm{H}_{2} \mathrm{~S}$ conversion and energy efficiency of $\mathrm{H}_{2} \mathrm{~S}$ decomposition in this pulsed corona discharge reactor varied at constant power due to the selected values of the electrical parameters of pulse forming capacitance, charge voltage, and pulse frequency. Low pulse forming capacitance, low charge voltage, and high pulse frequency operation produce the highest energy efficiency for $\mathrm{H}_{2} \mathrm{~S}$ conversion at constant power. $\mathrm{H}_{2} \mathrm{~S}$ conversion is more efficient in Ar- $\mathrm{N}_{2}$ gas mixtures than in $\mathrm{Ar}$ or $\mathrm{N}_{2}$. These results can be explained by corona discharge observations, the electron attachment reactions of $\mathrm{H}_{2} \mathrm{~S}$ at the streamer energies, and a proposed reaction mechanism of $\mathrm{H}_{2} \mathrm{~S}$ dissociation in the Ar$\mathrm{N}_{2}$ gas mixture. The energy consumption per molecule of converted $\mathrm{H}_{2} \mathrm{~S}$ in an equimolar mixture of $\mathrm{Ar}$ and $\mathrm{N}_{2}$ is the lowest that has been reported for any plasma reactor operated at non-vacuum pressures. The results reveal the potential for energy efficient $\mathrm{H}_{2} \mathrm{~S}$ decomposition in pulsed corona discharge reactors.
\end{abstract}

\section{Keywords}

Hydrogen sulfide dissociation; Nonthermal plasma; Pulsed corona discharge; Energy efficiency; Hydrogen production

\footnotetext{
*Corresponding author. E-mail: mdargyle@uwyo.edu, tel: 307-766-2973, fax: 307-766-6777
} 


\section{Introduction}

The annual demand for hydrogen in the U.S. chemical and refining industries for 2005 was about 8.2 million metric tons (2005), mainly for use as a reactant in the synthesis of ammonia and methanol and in petroleum hydrodesulfurization, hydrocracking, and upgrading processes. Merchant hydrogen production for use in refineries and chemical plants was about 1.4 million metric tons per year (2005). Although the total hydrogen consumption is growing at about 4 percent annually, growth in the merchant hydrogen business is higher, estimated to be about 10 percent, as refineries shift away from captive hydrogen production (2008). With the cost of sweet crude oil increasing, refineries are processing more heavy sour crude, which requires additional hydrogen for sulfur removal. Legislation limiting sulfur content in gasoline and diesel require more hydrotreating process steps in refineries. In addition, as hydrogen is being developed as an energy carrier, the predominant hydrogen production method, steam reforming of natural gas, may be insufficient for future needs. For example, by 2040, the use of hydrogen in fuel cell powered cars and light trucks is anticipated to require annual production of approximately 136 million metric tons of hydrogen (2004).

Hydrogen sulfide $\left(\mathrm{H}_{2} \mathrm{~S}\right)$ is a common contaminant (from ppm concentrations to $90 \%$ by volume) in many of the world's natural gas wells. In natural gas processing, it is viewed as a pollutant because it corrodes pipelines and deactivates metal-based catalysts used in steam methane reformation (Huang and T-Raissi, 2008). Traditionally, $\mathrm{H}_{2} \mathrm{~S}$ is converted via the Claus process to sulfur and water, resulting in a loss of the hydrogen content of the $\mathrm{H}_{2} \mathrm{~S}$ as low-grade steam. $\mathrm{H}_{2} \mathrm{~S}$ would be more economically valuable if 
both hydrogen and sulfur could be recovered. We estimate the U.S. $\mathrm{H}_{2} \mathrm{~S}$ production rate from natural gas plants and oil refineries to be on order of 10 million metric tons per year. The theoretical energy required to produce hydrogen from $\mathrm{H}_{2} \mathrm{~S}$ is only $20.63 \mathrm{~kJ} / \mathrm{mol} \mathrm{H}_{2}$ as compared to $63.17 \mathrm{~kJ} / \mathrm{mol} \mathrm{H}_{2}$ for steam methane reforming and $285.83 \mathrm{~kJ} / \mathrm{mol} \mathrm{H}_{2}$ for water electrolysis, all calculated from standard heats of formation at $298 \mathrm{~K}$ (Smith and Van Ness, 1987). Therefore, $\mathrm{H}_{2} \mathrm{~S}$ represents a significant potential future source of lowcost hydrogen, if efficient processes are developed to extract and recover the $\mathrm{H}_{2}$.

$\mathrm{H}_{2} \mathrm{~S}$ decomposition in various types of plasma reactors has been investigated as a method to recover the $\mathrm{H}_{2}$. Unfortunately, the reported energy consumptions are much higher than the theoretical energy requirement of $0.21 \mathrm{eV}$ per decomposed $\mathrm{H}_{2} \mathrm{~S}$ molecule (20.63 $\mathrm{kJ} / \mathrm{mol} \mathrm{H}_{2}$ ). All but one of the reported efficiencies exceed the energy requirement of $3.6 \mathrm{eV}$ per $\mathrm{H}_{2}$ molecule produced required for conventional steam methane reforming, the predominant hydrogen production method, with all separation equipment included (Cox et al., 1998). Dalaine et al., (1998a,b) investigated $\mathrm{H}_{2} \mathrm{~S}$ conversion in gas systems with concentrations of $0-100 \mathrm{ppm} \mathrm{H}_{2} \mathrm{~S}$ in air using gliding arc discharges. This type of reactor is rather inefficient, with an energy consumption of $500 \mathrm{eV} / \mathrm{H}_{2} \mathrm{~S}$ molecule dissociated. A large amount of work on microwave decomposition of $\mathrm{H}_{2} \mathrm{~S}$ was carried out in the former Soviet Union (Asisov et al., 1985; Bagautdinov et al., 1992, 1993a,b, 1995, 1998). Very low energy consumptions of $0.76 \mathrm{eV} / \mathrm{H}_{2} \mathrm{~S}$ were reported in both laboratory and pilot units used for the decomposition of pure $\mathrm{H}_{2} \mathrm{~S}$ or mixtures with $\mathrm{CO}_{2}$. Encouraged by these reports of high conversions and low energy requirements, a joint project for $\mathrm{H}_{2} \mathrm{~S}$ conversion using microwave plasmas was undertaken by the Alberta Hydrogen Research Program, Atomic Energy of Canada, and Shell Canada Limited. 
Unfortunately, this group reported the energy consumption for $\mathrm{H}_{2} \mathrm{~S}$ conversion to be about $\sim 4.5 \mathrm{eV} / \mathrm{H}_{2} \mathrm{~S}$ (Cox et al., 1998) and thus was unable to reproduce the low energy consumption reported by the Russian researchers. All microwave plasma experiments for $\mathrm{H}_{2} \mathrm{~S}$ conversion in the Canadian studies were performed at pressures below 1 atmosphere, which requires additional energy consumption for compression and vacuum costs. Traus and Suhr (1992) and Traus et al. (1993) investigated conversion of $\mathrm{H}_{2} \mathrm{~S}$ at 10-100 mol\% concentrations in $\mathrm{Ar}, \mathrm{N}_{2}$, and $\mathrm{H}_{2}$ in a silent discharge reactor and in a rotating glow discharge reactor. They found that the energy consumption for $\mathrm{H}_{2} \mathrm{~S}$ conversion in a rotating glow discharge reactor $\left(\sim 27 \mathrm{eV} / \mathrm{H}_{2} \mathrm{~S}\right)$ is less than that in a silent discharge reactor ( $\left.\sim 81 \mathrm{eV} / \mathrm{H}_{2} \mathrm{~S}\right)$. In addition, Abolentsev et al. (1995) and Ma et al. (2001) investigated decomposition of low (ppm) concentrations of $\mathrm{H}_{2} \mathrm{~S}$ in different balance gases, including air, $\mathrm{N}_{2}, \mathrm{H}_{2}$, He, and $\mathrm{CH}_{4}$, using a silent discharge reactor. $\mathrm{H}_{2} \mathrm{~S}$ conversion in pulsed corona discharge reactors was also studied by several investigators (Averin et al., 1996; Helfritch, 1993; Ruan et al., 1999; Wiseman and Douglas, 1972). These investigations were conducted at low $\mathrm{H}_{2} \mathrm{~S}$ concentrations ( $<2 \mathrm{~mol} \%$ ) with high $\left(>100 \mathrm{eV} / \mathrm{H}_{2} \mathrm{~S}\right)$ energy consumption, which are not practical conditions for commercial application.

We previously reported the lowest energy consumption of $17.4 \mathrm{eV} / \mathrm{H}_{2} \mathrm{~S}$ molecule for moderately high concentrations of $\mathrm{H}_{2} \mathrm{~S}, 16 \% \mathrm{H}_{2} \mathrm{~S}$ in $\mathrm{Ar}$, (Zhao et al., 2007) at nonvacuum pressures (134 $\mathrm{kPa})$. Also, at higher $\mathrm{H}_{2} \mathrm{~S}$ concentrations (>16 mol \%), $\mathrm{H}_{2} \mathrm{~S}$ decomposition in Ar produced higher conversions and reaction rates, as compared to those in $\mathrm{He}, \mathrm{N}_{2}$, and $\mathrm{H}_{2}$. Therefore, Ar was selected as the balance gas for most of the future experiments. Although Ar can be separated from $\mathrm{H}_{2} \mathrm{~S}$ and $\mathrm{H}_{2}$ at the reactor outlet 
and recycled to the process, it is relatively expensive compared to $\mathrm{N}_{2}$. Therefore, $\mathrm{Ar}$ diluted with $\mathrm{N}_{2}$ was also used as a balance gas with improved performance.

The electrical parameters of charge voltage $\left(V_{c}\right)$, pulse frequency $(f)$, and pulse forming capacitance $\left(C_{p}\right)$ have been reported to impact the conversion of various reactants in plasma reactors. For methane conversion, the moles of methane converted per unit of energy supplied decreased with increasing charge voltage and increased with increasing pulse-frequency (Ma et al., 2001), while methane conversion and energy efficiency were higher at a pulse forming capacitance of $1280 \mathrm{pF}$ as compared to $1920 \mathrm{pF}$ at different power inputs (Zhao et al., 2006b). $\mathrm{H}_{2} \mathrm{~S}$ conversion increased with increasing charge voltage for ppm concentrations of $\mathrm{H}_{2} \mathrm{~S}$ in an ozonizer (Haas and Khalafalla, 1973). NO conversion at ppm concentrations (Mok, 2000) increased with increasing pulse frequency and capacitance. In all these studies, the total power supplied to the reactor changed as each of these parameters changed because power input is defined as $P$ $=1 / 2 C_{p} V_{c}^{2} f$, where $C_{p}$ is the pulse forming capacitance, $V_{c}$ is the charge voltage, and $f$ is the pulse frequency. This study reports the effect of these parameters at constant power to isolate the effects on $\mathrm{H}_{2} \mathrm{~S}$ conversion as these parameters were varied at constant power input.

\section{Experimental}

The experimental system, shown in Figure 1, consists of a stainless steel reactor, a flow control and distribution system, and an electrical system. The reactor is a vertical wire-in-tube design, with gas flow from top to bottom. The anode is a $0.001 \mathrm{~m}$ diameter stainless steel wire passing axially through the center of the cathode tube. The cathode is 
a stainless steel tube, $0.024 \mathrm{~m}$ in diameter and $0.889 \mathrm{~m}$ long, with 7 quartz view-ports and 7 ports for sampling and temperature measurement placed equidistantly along its length. The $0.01 \mathrm{~m}$ diameter quartz view-ports permitted visual inspection of the corona discharge. At the same operating conditions, similar $\mathrm{H}_{2} \mathrm{~S}$ conversions were obtained in geometrically similar cathode tubes, with and without ports, indicating negligible effect of the cathode viewports on the corona discharge. The stems of the bimetallic thermometers were immersed about $0.025 \mathrm{~m}$ into tees to be flush with the cathode tube inner wall. The thermometers proved to be unresponsive and displayed near ambient temperatures even when the tube was warm to touch.

Gas mixtures entered the reactor at ambient temperature $(\sim 300 \mathrm{~K})$ and a controlled flow rate $\left(1.18 \times 10^{-4} \mathrm{SCMs}^{-1}\right)$. The pressure in the reactor was maintained at $134 \mathrm{kPa}$ by a back pressure regulator. The $\mathrm{H}_{2} \mathrm{~S}$ in Ar gas mixture was prepared by mixing ultra high purity (UHP) $\mathrm{H}_{2} \mathrm{~S}$ (Airgas) with UHP Ar (US Welding). The desired entrance mole fraction of $\mathrm{H}_{2} \mathrm{~S}$ was set with two well-calibrated mass flow controllers (Brooks Mf50x \& Mf51x). The reactant and product gases were analyzed with a mass spectrometer (Stanford Research Systems QMS 100 Series Gas Analyzer). To perform quantitative measurements, an internal standard method (Watson, 1997) was used to calibrate the ion signal response at an $\mathrm{m} / \mathrm{z}$ ratio of 34 with the $\mathrm{H}_{2} \mathrm{~S}$ mole fraction, in which Ar was used as an internal standard. For experiments involving mixtures of nitrogen, UHP $\mathrm{N}_{2}$ was introduced to the $\mathrm{H}_{2} \mathrm{~S}-\mathrm{Ar}$ mixture by a calibrated rotameter. The mixture compositions used for the $\mathrm{H}_{2} \mathrm{~S}$ decomposition experiments involving nitrogen are shown in Table 1. The mass spectrometer was calibrated for $\mathrm{H}_{2} \mathrm{~S}$ concentrations ranging from $4 \%$ to $10 \%$ in $23 \% \mathrm{~N}_{2}$ (balance Ar), $46 \% \mathrm{~N}_{2}$ (balance $\mathrm{Ar}$ ), and $69 \% \mathrm{~N}_{2}$ (balance $\mathrm{Ar}$ ). For 
the gas mixture 5 in Table $1, \mathrm{~N}_{2}$ was used as an internal standard to calibrate the mass spectrometer.

The structure of sulfur deposits in the reactor was analyzed by an X-ray diffractometer (SCINTAG XDS2000 producing Cu $\mathrm{K}_{\alpha}$ X-rays and equipped with a thetatheta goniometer and a solid state X-ray detector).

The reactor electrical circuit diagram is shown in Figure 2. The electrical system produces a positive DC pulsed corona discharge and is capable of delivering charge voltages from $6.9 \mathrm{kV}$ to $30 \mathrm{kV}$ and pulse frequencies from 0 to $1000 \mathrm{~Hz}$. It consists of a high voltage DC power supply, a capacitive energy storage medium, and a hydrogen thyratron connected to the reactor. A $40 \mathrm{kV}$ oil-cooled, high voltage supply charges the capacitor bank, which could be increased in four increments of 720 pF (using TDK FHV10AN capacitors). The hydrogen thyratron (L-3 Electron Devices Type L-4945) is an electrical switch that uses hydrogen gas as the switching medium. The switching action is achieved by a shift from the insulating properties of neutral gas to the conducting properties of ionized gas. The thyratron is designed to withstand a high voltage in the 'off' state, to trigger at a precisely defined time, to pass high peak current pulses in the 'on' state, and to recover rapidly to the 'off' state to allow high repetition rate operation (2002). When the thyratron triggers, the stored energy in the capacitor bank is discharged in a few nanoseconds to the anode, which creates the plasma in the gas flowing through the reactor tube. The formation of corona discharge can be detected by a discharge waveform recorder (Tektronix TDS 220). The energy released by the capacitors per pulse was calculated as $1 / 2 C_{p} V_{c}^{2}$, where $C_{p}$ is the pulse forming capacitance in $\mathrm{pF}$, and $V_{c}$ is the constant charge voltage before discharge in volts. The power consumed, $W\left(\mathrm{~J} \cdot \mathrm{s}^{-1}\right)$, 
was calculated as the product of the input energy per pulse $\left(1 / 2 f C_{p} V_{c}^{2}\right.$,) and the pulse frequency $(f)$ in Hz. Tables 2 and 3 show the electrical parameters for the constant power (100 W) experiments and the experiments involving nitrogen, respectively.

The charging capacitors, limiting resistor, hydrogen thyratron switch, and electrical connections to the reactor were all enclosed in Teflon. The Teflon insulation ensures very low stray capacitance in the range of 0.1 to $0.5 \mathrm{pF}$ because of its high dielectric strength. The electrical lines connecting the capacitors, thyratron, and reactor are solid steel rods enclosed in Teflon, again ensuring very low stray capacitance and low inductance.

\section{Results and Discussion}

\subsection{Visual observations of the corona reactor}

The corona discharge was visible around the wire through the viewports, as shown in Figure 3. Visual observation confirmed that intensity of the discharge was not uniform along the length of the tube. The corona was not observed in all viewports simultaneously during the discharge duration. The location of the brightest and constant discharge depends on the type of gas, concentration of individual gases in the case of mixtures, and charge voltage. In pure Ar, the brightest and constant discharge occurred in the upper region (0.3-0.6 $\mathrm{m}$ from the top of the reactor), while in pure $\mathrm{N}_{2}$, the discharge occurred in the lower region (0.3-0.6 $\mathrm{m}$ from the bottom of the reactor). These observations were interpreted with respect to the molecular structure of these gases, as Ar is monatomic while $\mathrm{N}_{2}$ is diatomic. As the gases travel through the cathode tube from top to bottom, they interact with the electrons energized by the pulsed electric field 
between the wire and the tube. In a monatomic gas, like Ar, electrons predominantly experience elastic collisions with Ar atoms without energy loss, if the electron energy is less than the energy (11.6 eV) (Fridman and Kennedy, 2004d) of the lowest electronically excited state of $\operatorname{Ar}, \operatorname{Ar}\left({ }^{3} \mathrm{P}_{2}\right)$. The electrons that experience these elastic collisions are further accelerated and hence gain more energy in the electric field. When electron energy exceeds the excitation energy $(11.6 \mathrm{eV})$ required to excite ground state argon to $\operatorname{Ar}\left({ }^{3} \mathrm{P}_{2}\right)$, the electrons may experience inelastic collisions and lose kinetic energy. In contrast, when energetic electrons collide with diatomic molecules, like $\mathrm{N}_{2}$, the electrons may lose energy through many other processes unavailable to monatomic species, such as dissociation (10 eV) (Ma et al., 2001), electronic excitation of lower energy transitions ( 6.1-12 eV) (Zhao et al., 2004), rotation $\left(\sim 10^{-4}-10^{-5} \mathrm{eV}\right)$ (Fridman and Kennedy, 2004c), and vibration (1.7-3.5 eV) (Fridman and Kennedy, 2004c), depending on the electron energy. This implies that electron energy cannot be accumulated in diatomic balance gases to the same levels as in monatomic gases. Therefore, diatomic gases, such as $\mathrm{N}_{2}$, have to travel further through the applied electric field within the tube before a corona discharge can occur. Hence, the brightest discharge in $\mathrm{N}_{2}$ takes place lower in the reactor than in Ar. This explanation also describes the observed downward shift of the brightest discharge in Ar on dilution with a polyatomic gas like $\mathrm{H}_{2} \mathrm{~S}$.

In an earlier study of positive streamers in ozone for a wire-plate pulsed corona discharge system (Winands et al., 2006), the thickness, intensity, and velocity of primary streamers increased as the applied voltage increased. The number of streamers leaving the anode also increased, but the number reaching the cathode was independent of voltage. In the same study, pulse frequencies up to $400 \mathrm{~Hz}$ had no effect on the diameter, 
intensity, and number of streamers. This implies an increase in primary streamer volume with voltage which could potentially increase conversion. Although we did not measure the thickness, intensity, and velocity of streamers, we observed that the number of viewports where corona could be seen decreased with an increase in the charge voltage. As charge voltage is increased from $11 \mathrm{kV}$ to $21 \mathrm{kV}$, the discharge moved from the lower portion of the reactor to the upper portion. This increase in voltage causes an increase in the electric field around the wire, which imparts more energy to the electrons, causing the corona discharge to occur earlier as the gas flows from top to bottom. At lower voltages (11 kV, $13 \mathrm{kV} \& 15 \mathrm{kV}$ ), the corona discharge was observed through 2, 3, or even 4 view ports in the middle and lower regions of the reactor, while the remaining view ports were dark. At higher voltages ( $17 \mathrm{kV}, 19 \mathrm{kV} \& 21 \mathrm{kV})$, the corona was seen only in the upper region through 1 or 2 view ports. This indicates that the plasma volume in the reactor increases with decreasing voltage and increasing frequency. Thus, the reactor volume is used more efficiently in this condition as indicated by an increase in conversion, discussed below.

\section{2. $\mathrm{H}_{2} \mathrm{~S}$ conversion in Ar increases with decreasing charge voltage and} increasing pulse frequency at constant pulse forming capacitance and power

Figures 4(a) and 4(b) show the effect of increasing charge voltage on $\mathrm{H}_{2} \mathrm{~S}$ conversion for four different values of capacitance. Figure 4(a) contains data for $8 \mathrm{~mol} \%$ $\mathrm{H}_{2} \mathrm{~S}$ in Ar, while Figure 4(b) contains data for $12 \mathrm{~mol} \% \mathrm{H}_{2} \mathrm{~S}$ in Ar. For any particular value of capacitance, the $\mathrm{H}_{2} \mathrm{~S}$ conversion decreased with increasing charge voltage, which corresponds to decreasing pulse frequency at a constant power input of $100 \mathrm{~W}$. High pulse frequency and low charge voltage conditions were the best for $\mathrm{H}_{2} \mathrm{~S}$ 
conversion for all values of pulse forming capacitances. The highest conversions obtained were $27.7 \%$ for the $8 \% \mathrm{H}_{2} \mathrm{~S}-92 \% \mathrm{Ar}$ and $24.9 \%$ for the $12 \% \mathrm{H}_{2} \mathrm{~S}-92 \% \mathrm{Ar}$ mixtures. The proposed explanation for this behavior is based on the energy of electrons in the streamers.

In pulsed corona discharges in air and flue gas, a difference in the streamer characteristics with increasing charge voltage has been reported (Yan et al., 1998). Streamers are thin ionized luminous channels formed between the electrodes. They are of two types: primary and secondary. For our case with a positive pulsed corona discharge, the streamers propagate from the wire (anode) to the tube (cathode) within tens of nanoseconds. The primary streamers carry high energy electrons $(\sim 10 \mathrm{eV})$, while secondary streamers carry low energy electrons ( 1-3 eV) (Winands et al., 2006). Secondary streamers develop when the primary streamers approach the cathode (Yan et al., 1998). With increasing charge voltage, the average streamer propagation velocity increases, resulting in a decrease in the duration of primary streamer propagation (Yan et al., 1998). This increase in streamer velocity due to increasing voltage is supported by the decrease in duration of the primary streamer discharge observed in the discharge voltage waveform during methane conversion in a pulsed corona discharge reactor (Yao et al., 2001). As the primary streamers die out faster with increasing voltages, the secondary streamers start developing at higher voltages. Thus, at higher charge voltages, both primary and secondary streamers are formed, while at lower charge voltages, only primary streamers are formed. This behavior has been reported in both wire-plate and wire-cylinder reactors, irrespective of power system specifications (Yan et al., 1998). Therefore, the low charge voltage condition produces more electrons with an average 
energy of $10 \mathrm{eV}$, which is closer to the excitation energy $(11.6 \mathrm{eV})$ for the lowest electronically excited state of $\operatorname{Ar}\left(\operatorname{Ar}\left({ }^{3} \mathrm{P}_{2}\right)\right)$ and higher than the electron energy range (8-9 eV) in which the maxima in the absolute total electron-scattering cross section for $\mathrm{H}_{2} \mathrm{~S}$ occurs $\left(\sigma_{\max }=40 \times 10^{-20} \mathrm{~m}^{2}\right)$ (Szmytkowski et al., 2003). These electron energies are more than sufficient for dissociation of $\mathrm{H}_{2} \mathrm{~S}$ into $\mathrm{HS}$ and $\mathrm{H}$ because the $\mathrm{H}-\mathrm{SH}$ bond strength at $298 \mathrm{~K}$ is $3.96 \mathrm{eV}$ (Lide, 2003). Excitation of Ar and direct dissociation of $\mathrm{H}_{2} \mathrm{~S}$ by electron impact have been proposed as the two initiating mechanisms responsible for $\mathrm{H}_{2} \mathrm{~S}$ decomposition in $\mathrm{Ar}$ (Zhao et al., 2007).

The rates of dissociative electron attachment reactions of $\mathrm{H}_{2} \mathrm{~S}$ are higher with electrons in the secondary streamer than with electrons in the primary streamer. The dissociative electron attachment reactions of $\mathrm{H}_{2} \mathrm{~S}$ with the low energy $(\sim 1-3 \mathrm{eV})$ electrons of the secondary streamers and the high energy electrons $(\sim 10 \mathrm{eV})$ of the primary streamers are shown in Table 4 (Rao and Srivastava, 1993). These processes are likely in our reactor because the appearance potentials of the ions (defined as the minimum energy of the electrons in the ionizing beam necessary to produce a given fragment ion) are lower than or approximately equal to the energy of the electrons in the streamer. The approximate cross sections shown in Table 4 correspond to the energies of electrons in the primary and secondary streamers. $\mathrm{HS}^{-}$formation due to dissociative electron attachment processes occurs at a faster rate ( 2 orders greater, based on the data in Table 4) within secondary streamers due to its greater cross section, while $S^{-}$formation will occur at similar rates compared to the reactions in the primary streamers. Such electron attachment processes are considered essential in weakly ionized plasmas, like corona discharges, with low electron concentrations and low degrees of ionization and are first 
order with respect to electron concentration (Fridman and Kennedy, 2004b). As these processes capture electrons and decrease their concentration, the rates of electron collision reactions decrease, as observed previously (Zhao et al., 2005b,c) and may reduce $\mathrm{H}_{2} \mathrm{~S}$ decomposition rate, as suggested previously (Zhao et al., 2007). In the primary streamers, the decrease in electron concentration by dissociative electron attachment is more than compensated by the direct electron collision ionization of $\mathrm{H}_{2} \mathrm{~S}$ leading to $\mathrm{H}_{2} \mathrm{~S}^{+}$production. The cross section of this ionization process is at least two orders of magnitude higher than that of the electron attachment processes in primary streamers (see Table 4). Other positive ion formation by electron-impact dissociative ionization is unlikely in our reactor because the appearance potentials for $\mathrm{HS}^{+}, \mathrm{S}^{+}, \mathrm{H}^{+}$, $\mathrm{H}_{2}^{+}, \mathrm{H}_{2} \mathrm{~S}^{++}$, and $\mathrm{S}^{++}$ions are $14.35 \mathrm{eV}, 13.45 \mathrm{eV}, 15.50 \mathrm{eV}, 16.50 \mathrm{eV}, 32.00 \mathrm{eV}$, and $40.50 \mathrm{eV}$, respectively (Rao and Srivastava, 1993), which are all significantly greater than the average energy $(10 \mathrm{eV})$ of electrons in the primary streamer.

Energy efficiency has previously been suggested to decrease with secondary streamer formation. For example, for ppm-concentration $\mathrm{SO}_{2}$ removal in pulsed corona discharges, the energy utilization efficiency decreased with increasing charge voltage (Bingyan et al., 2005). Energy utilization efficiency is defined as the ratio of the primary streamer energy to the total pulse discharge energy. Two peaks have been reported in the discharge voltage, discharge current, and power waveforms from an oscilloscope over the pulse duration. The first and the second peaks represent the primary streamers and the secondary streamers, respectively (Bingyan et al., 2005; Yao et al., 2001). The primary streamer energy is calculated by integrating the first power peak, while the total pulse discharge energy is calculated by integrating the discharge power waveform. Analogous 
to $\mathrm{SO}_{2}$ removal, the observed decrease in conversion (Figure 4) at higher voltages is likely due to additional energy being used in secondary streamer formation, thereby reducing the energy utilization efficiency.

In these experiments, any increase in charge voltage is accompanied by a decrease in pulse forming frequency to keep the input power constant. Consistent with the data shown in Figure 4, the decrease in conversion at higher charge voltages is likely caused by formation of energy-inefficient secondary streamers. Thus, although the power supplied to the pulsed corona reactor is the same, low voltage and high frequency operating conditions are desirable for $\mathrm{H}_{2} \mathrm{~S}$ decomposition to maximize energy efficiency by minimizing secondary streamer formation.

\subsection{Energy consumption for $\mathrm{H}_{2} \mathrm{~S}$ conversion in Ar decreases with decreasing pulse forming capacitance at constant power.}

Figure 5 shows the energy consumption per $\mathrm{H}_{2} \mathrm{~S}$ molecule converted as a function of charge voltage for four values of pulse forming capacitance, again at constant power input of $100 \mathrm{~W}$, for $8 \mathrm{~mol} \% \mathrm{H}_{2} \mathrm{~S}$ in $\mathrm{Ar}$ (Figure 5(a)) and for $12 \mathrm{~mol} \% \mathrm{H}_{2} \mathrm{~S}$ in $\mathrm{Ar}$ (Figure 5(b)). The energy consumption decreases with decreasing pulse forming capacitance values at constant power. For example, for the $12 \% \mathrm{H}_{2} \mathrm{~S}-88 \%$ Ar mixture, at a constant charge voltage of $17 \mathrm{kV}$, the energy consumption at $720 \mathrm{pF}$ is only $8.2 \mathrm{eV} / \mathrm{H}_{2} \mathrm{~S}$ molecule compared to $15 \mathrm{eV} / \mathrm{H}_{2} \mathrm{~S}$ molecule at $2880 \mathrm{pF}$. The lowest pulse forming capacitance (720 pF) tested provides the least energy consumption per $\mathrm{H}_{2} \mathrm{~S}$ molecule converted (9.8 $\mathrm{eV} / \mathrm{H}_{2} \mathrm{~S}$ for the $8 \% \mathrm{H}_{2} \mathrm{~S}-92 \%$ Ar mixture and $7.3 \mathrm{eV} / \mathrm{H}_{2} \mathrm{~S}$ for the $12 \% \mathrm{H}_{2} \mathrm{~S}-88 \% \mathrm{Ar}$ mixture), which corresponds to the highest energy efficiency. This phenomenon can be 
explained by the optimum energy transfer condition proposed by Uhm and Lee (1997) and by Mok (2000).

In their analytical investigation of corona discharge systems, (Uhm and Lee, 1997) reported the optimum energy transfer condition as

$$
2 \frac{C_{e}}{C_{R 0}}=1+2 \frac{\ln \left(R_{0} / R_{c}\right)}{\ln (1.11 \zeta)}
$$

where, $C_{e}$ is the capacitance of the external circuit (pulse-forming capacitance), $C_{R 0}$ is the initial capacitance of the reactor chamber, $R_{0}$ is the radius of the wire, $R_{c}$ is the radius of the tube, and $\zeta$ is the normalized plasma mobility, which is related to the ionization front velocity. The normalized plasma mobility is proportional to the pulse-forming capacitance and is inversely proportional to the reactor volume.

In Mok’s experimental study of ppm-concentration NO decomposition in a wireplate reactor (Mok, 2000), he calculated the initial capacitance of the reactor $\left(C_{R 0}\right)$ by measuring the discharge voltage and current, when the charge voltage is lower than the corona onset value, as follows:

$$
I_{\text {cap }}=C_{R O} \frac{d V}{d t}
$$

where, $I_{\text {cap }}$ is the measured capacitive current and $d V / d t$ is the rate of change in the discharge voltage. As the charge voltage applied was less than the corona onset value, the measured current was purely capacitive and did not include corona current. Mok found that the reactor capacitance increased and reached a value three times the initial reactor capacitance during the corona discharge. Further, he found that the energy transferred from the pulse-forming capacitance to the reactor reached a maximum when the pulse-forming capacitance was three times the initial capacitance of the reactor. He 
verified this by electrical measurements and by the NO decomposition experiment by increasing pulse-forming capacitance. As a result, he proposed the optimum energy transfer condition as,

$$
\frac{\text { Pulse - forming capacitance }\left(\mathrm{C}_{\mathrm{P}}\right)}{\text { Initial capacitance of reactor }\left(\mathrm{C}_{\mathrm{R} 0}\right)} \approx 3
$$

The initial capacitance of the reactor $\left(C_{R 0}\right)$ can be calculated using a capacitance formula for the wire-in-tube geometry (Shin et al., 2000):

$$
C_{R 0}=\frac{2 \pi k \varepsilon_{0} L}{\ln (R / r)} \approx 16.7 p F
$$

Here, $R$ is the cathode tube radius ( $0.012 \mathrm{~m}), r$ is the anode wire radius $(0.00057 \mathrm{~m}), L$ is the reactor length $(0.914 \mathrm{~m}), \varepsilon_{0}$ is the permittivity of free space $\left(8.854 \times 10^{-12} \mathrm{~F} / \mathrm{m}\right)$, and $k$ is the dielectric constant of the mixture of $\mathrm{H}_{2} \mathrm{~S}$ and $\operatorname{Ar}(\sim 1)$. For our case of high concentration $\mathrm{H}_{2} \mathrm{~S}$ decomposition in $\mathrm{Ar}$ at constant power, results similar to the ppmconcentration NO decomposition were obtained. However, in the present study, the capacitance was increased to maintain constant power input by decreasing charge voltage and frequency, unlike in Mok's work. Thus, at $720 \mathrm{pF}$ capacitance, a higher fraction of the $100 \mathrm{~W}$ of supplied energy is transferred into the reactor, resulting in higher $\mathrm{H}_{2} \mathrm{~S}$ conversion and lower energy consumption. Table 5 shows representative data of energy consumption as a function of the pulse forming capacitance and the capacitance ratio (pulse forming capacitance/reactor capacitance) for the four values of pulse forming capacitance used in this study. Figure 6 shows the representative data graphically. Although the capacitance ratio for the reactor used in this study is far from the optimum proposed by Mok, the trend of decreasing energy consumption (corresponding to 
increasing energy efficiency) as the capacitance ratio approaches the optimum energy transfer ratio is clear.

\section{4. $\mathrm{H}_{2} \mathrm{~S}$ conversion in $\mathrm{N}_{2}$-Ar mixtures}

$\mathrm{H}_{2} \mathrm{~S}$ conversion is higher in monatomic gases (Ar and $\mathrm{He}$ ) than in diatomic gases ( $\mathrm{N}_{2}$ and $\mathrm{H}_{2}$ ) (Zhao et al., 2007). At high $\mathrm{H}_{2} \mathrm{~S}$ concentrations (>16\%), $\mathrm{H}_{2} \mathrm{~S}$ conversion in Ar was the highest. However, as $\mathrm{Ar}$ is more expensive than $\mathrm{N}_{2}$, the process could be more economical if Ar were diluted with $\mathrm{N}_{2}$ and comparable $\mathrm{H}_{2} \mathrm{~S}$ conversions to that in pure Ar could be obtained. Further, energy efficiency might be further improved by establishing a corona in more of the reactor volume. As noted earlier, the corona was observed only in the upper region of the reactor in a pure monatomic gas (Ar) and only in the lower region in a pure molecular gas $\left(\mathrm{N}_{2}\right)$. If it were possible to produce a corona along the entire length of the reactor, the plasma volume would increase which should increase $\mathrm{H}_{2} \mathrm{~S}$ conversion at a given input power. This hypothesis was explored by mixing a molecular gas $\left(\mathrm{N}_{2}\right)$ with a monatomic gas $(\mathrm{Ar}) . \mathrm{H}_{2} \mathrm{~S}$ is not a suitable candidate as a molecular gas because of its high dielectric strength ( 2.9) (Christophorou et al., 1987) and is already present as the reactant. Therefore, $\mathrm{N}_{2}$ was mixed with $\mathrm{Ar}$ and $\mathrm{H}_{2} \mathrm{~S}$ to increase plasma volume and $\mathrm{H}_{2} \mathrm{~S}$ conversion.

$\mathrm{H}_{2} \mathrm{~S}$ decomposition was performed in various concentrations of $\mathrm{Ar}$ and $\mathrm{N}_{2}$ at three different input power values $(60 \mathrm{~W}, 80 \mathrm{~W}$, and $100 \mathrm{~W})$ to verify repeatability of the results. The $\mathrm{H}_{2} \mathrm{~S}$ conversion and energy consumption at the three input powers as a function of composition for the four mixtures are shown in Figures 7 and 8, respectively. The $\mathrm{H}_{2} \mathrm{~S}$ conversion initially increases with increasing addition of $\mathrm{N}_{2}$, reaches a maximum for the $46 \% \mathrm{~N}_{2}-46 \%$ Ar mixture, and then decreases (Figure 7). As the energy 
consumption is inversely proportional to the $\mathrm{H}_{2} \mathrm{~S}$ conversion, energy consumption initially decreases with increasing addition of $\mathrm{N}_{2}$, reaches a minimum for the $46 \% \mathrm{~N}_{2}$ 46\% Ar mixture, and then increases. Consistent with our earlier experiments (Zhao et al., 2007), the $\mathrm{H}_{2} \mathrm{~S}$ conversion in $\mathrm{N}_{2}$ is lower than in Ar. The deviation of conversion for 60 $\mathrm{W}$ input power, which for $92 \% \mathrm{~N}_{2}$ is slightly higher than that at $80 \mathrm{~W}$ input power, is not significant because these data points fall within the experimental uncertainty of $+/-10 \%$ at a 95\% confidence interval.

The location of the brightest and constant discharge and the number of viewports through which corona was observed, changed with the feed gas composition. As the $\mathrm{N}_{2}$ concentration was increased from zero, the brightest and constant discharge descended. For example, at $100 \mathrm{~W}$, the top two viewports for the $8 \% \mathrm{H}_{2} \mathrm{~S}-92 \% \mathrm{Ar}$ and the $8 \% \mathrm{H}_{2} \mathrm{~S}$ $23 \% \mathrm{~N}_{2}-69 \%$ Ar mixtures were lit, while the 5th and 6th viewports were lit for the $8 \%$ $\mathrm{H}_{2} \mathrm{~S}-69 \% \mathrm{~N}_{2}-23 \% \mathrm{Ar}$ and the $8 \% \mathrm{H}_{2} \mathrm{~S}-92 \% \mathrm{~N}_{2}$ mixtures. More importantly, the number of viewports through which corona was observed, increased from two for the $8 \% \mathrm{H}_{2} \mathrm{~S}$ 92\% Ar mixture to five for $8 \% \mathrm{H}_{2} \mathrm{~S}-46 \% \mathrm{~N}_{2}-46 \%$ Ar mixture, and then decreased to three for $8 \% \mathrm{H}_{2} \mathrm{~S}-92 \% \mathrm{~N}_{2}$ mixture at $100 \mathrm{~W}$. Therefore, the plasma volume is greatest for the $46 \% \mathrm{~N}_{2}-46 \%$ Ar-8\% $\mathrm{H}_{2} \mathrm{~S}$ mixture, filling approximately $70 \%$ of the reactor, compared to $40 \%$ for the $8 \% \mathrm{H}_{2} \mathrm{~S}-92 \% \mathrm{~N}_{2}$ mixture and $30 \%$ for the $8 \% \mathrm{H}_{2} \mathrm{~S}-92 \% \mathrm{~N}_{2}$ mixture at 100 W. For the $8 \% \mathrm{H}_{2} \mathrm{~S}-46 \%$ Ar- $46 \% \mathrm{~N}_{2}$ feed mixture, the energy consumption was the lowest, at $6.0 \mathrm{eV} / \mathrm{H}_{2} \mathrm{~S}$ for $100 \mathrm{~W}, 5.3 \mathrm{eV} / \mathrm{H}_{2} \mathrm{~S}$ for $80 \mathrm{~W}$, and $4.9 \mathrm{eV} / \mathrm{H}_{2} \mathrm{~S}$ for $60 \mathrm{~W}$. This value of $4.9 \mathrm{eV} / \mathrm{H}_{2} \mathrm{~S}$ is the lowest reported value for $\mathrm{H}_{2} \mathrm{~S}$ decomposition at non-vacuum pressures for any $\mathrm{H}_{2} \mathrm{~S}$ concentration. 
For $\mathrm{H}_{2} \mathrm{~S}$-Ar mixtures, our previous investigation (Zhao et al., 2006a) concluded that the major product for direct electron collision with Ar is the lowest excited state of Ar, $\operatorname{Ar}\left({ }^{3} \mathrm{P}_{2}\right)$, which has an excitation energy of $11.55 \mathrm{eV}$.

$$
\mathrm{e}+\operatorname{Ar} \rightarrow \operatorname{Ar}\left({ }^{3} \mathrm{P}_{2}\right)+\mathrm{e}
$$

The $\operatorname{Ar}\left({ }^{3} \mathrm{P}_{2}\right)$ contributes to $\mathrm{H}_{2} \mathrm{~S}$ dissociation and $\mathrm{H}_{2}$ dissociation through Reactions $\mathrm{R} 2$ and R3 (Gundel et al., 1976; Velazco et al., 1978).

$$
\begin{array}{ll}
\operatorname{Ar}\left({ }^{3} \mathrm{P}_{2}\right)+\mathrm{H}_{2} \mathrm{~S} \rightarrow \mathrm{Ar}+\mathrm{H}+\mathrm{HS} & \mathrm{k}=5.18 \times 10^{14} \mathrm{~cm}^{3} \cdot \mathrm{mol}^{-1} \cdot \mathrm{s}^{-1} \\
\operatorname{Ar}\left({ }^{3} \mathrm{P}_{2}\right)+\mathrm{H}_{2} \rightarrow \mathrm{Ar}+\mathrm{H}+\mathrm{H} & \mathrm{k}=3.97 \times 10^{13} \mathrm{~cm}^{3} \cdot \mathrm{mol}^{-1} \cdot \mathrm{s}^{-1}
\end{array}
$$

For $\mathrm{H}_{2} \mathrm{~S}-\mathrm{N}_{2}$ mixtures, the major products from electron collision reaction with $\mathrm{N}_{2}$ are $\mathrm{N}$ radicals and the first electronic excited state of $\mathrm{N}_{2}, \mathrm{~N}_{2}(\mathrm{~A})$, which requires an excitation energy of $6.1 \mathrm{eV}$ (Zhao et al., 2004).

$$
\begin{aligned}
& \mathrm{e}+\mathrm{N}_{2} \rightarrow \mathrm{N}+\mathrm{N}+\mathrm{e} \\
& \mathrm{e}+\mathrm{N}_{2} \rightarrow \mathrm{N}_{2}(\mathrm{~A})+\mathrm{e}
\end{aligned}
$$

The previous investigation (Zhao et al., 2005a) reported that the rate of electron collision reaction $\mathrm{R} 5$ is about 7 times higher than that of R4. These active species react with $\mathrm{N}_{2}$, $\mathrm{H}_{2} \mathrm{~S}$, and $\mathrm{H}_{2}$ (Aleksandrov et al., 1994; Herron, 1999; Kossyi et al., 1992), according to the following reactions:

$$
\begin{array}{ll}
\mathrm{N}+\mathrm{H}_{2} \rightarrow \mathrm{NH}_{2} & \mathrm{k}=1.14 \times 10^{4} \mathrm{~cm}^{3} \cdot \mathrm{mol}^{-1} \cdot \mathrm{s}^{-1} \\
\mathrm{~N}+\mathrm{N} \rightarrow \mathrm{N}_{2} & \mathrm{k}=8.54 \times 10^{10} \mathrm{~cm}^{3} \cdot \mathrm{mol}^{-1} \cdot \mathrm{s}^{-1} \\
\mathrm{~N}_{2}(\mathrm{~A})+\mathrm{H}_{2} \rightarrow \mathrm{N}_{2}+2 \mathrm{H} & \mathrm{k}=2.11 \times 10^{9} \mathrm{~cm}^{3} \cdot \mathrm{mol}^{-1} \cdot \mathrm{s}^{-1} \\
\mathrm{~N}_{2}(\mathrm{~A})+\mathrm{H}_{2} \mathrm{~S} \rightarrow \mathrm{N}_{2}+\mathrm{H}+\mathrm{HS} & \mathrm{k}=1.81 \times 10^{14} \mathrm{~cm}^{3} \cdot \mathrm{mol}^{-1} \cdot \mathrm{s}^{-1}
\end{array}
$$


There are no reports of rate constants for reactions between $\mathrm{H}_{2} \mathrm{~S}$ and N. However, by analogy to the extremely low rate constant of the reaction between $\mathrm{N}$ and $\mathrm{H}_{2} \mathrm{O}\left(4 \times 10^{3}\right.$ $\mathrm{cm}^{3} \cdot \mathrm{mol}^{-1} \cdot \mathrm{s}^{-1}$ at $1073 \mathrm{~K}$ ) (Cohen and Westberg, 1991), we presume that $\mathrm{N}$ does not contribute significantly to $\mathrm{H}_{2} \mathrm{~S}$ conversion. The $\mathrm{N}$ atom radicals predominantly recombine to $\mathrm{N}_{2}$ because rate constant of R7 is about $8 \times 10^{6}$ higher than that of R6. In addition, no byproducts of ammonia were detected during our analysis, which confirms that the only significant products of $\mathrm{H}_{2} \mathrm{~S}$ conversion in $\mathrm{N}_{2}$ are $\mathrm{H}_{2}$ and $\mathrm{S}$.

For $\mathrm{H}_{2} \mathrm{~S}-\mathrm{Ar}-\mathrm{N}_{2}$ mixtures, the interaction of $\operatorname{Ar}\left({ }^{3} \mathrm{P}_{2}\right)$ with $\mathrm{N}_{2}$ and the interaction of Ar with the excited states of $\mathrm{N}_{2}$ can enhance $\mathrm{H}_{2} \mathrm{~S}$ decomposition. As confirmed with $\mathrm{H}_{2} \mathrm{~S}$-Ar and $\mathrm{H}_{2} \mathrm{~S}-\mathrm{N}_{2}$ mixtures, $\operatorname{Ar}\left({ }^{3} \mathrm{P}_{2}\right)$ and $\mathrm{N}_{2}(\mathrm{~A})$ appear to be directly involved in $\mathrm{H}_{2} \mathrm{~S}$ dissociation through reactions R2 and R5, respectively. $\operatorname{Ar}\left({ }^{3} \mathrm{P}_{2}\right)$ can collide with $\mathrm{N}_{2}$ to generate the excited state, $\mathrm{N}_{2}(\mathrm{C})$ (Velazco et al., 1978).

$$
\operatorname{Ar}\left({ }^{3} \mathrm{P}_{2}\right)+\mathrm{N}_{2} \rightarrow \mathrm{Ar}+\mathrm{N}_{2}(\mathrm{C}) \quad \mathrm{k}=2.17 \times 10^{13} \mathrm{~cm}^{3} \cdot \mathrm{mol}^{-1} \cdot \mathrm{s}^{-1}
$$

$\mathrm{N}_{2}(\mathrm{C})$ is transformed to $\mathrm{N}_{2}$ (B) either through radiative emission or through collisioninduced radiation.

$$
\begin{array}{ll}
\mathrm{N}_{2}(\mathrm{C}) \rightarrow \mathrm{N}_{2}(\mathrm{~B})+\mathrm{h} v & \mathrm{k}=2.73 \times 10^{7} \mathrm{~s}^{-1} \\
\mathrm{~N}_{2}(\mathrm{C})+\mathrm{Ar} \rightarrow \mathrm{N}_{2}(\mathrm{~B})+\mathrm{h} v & \mathrm{k}=8.19 \times 10^{11} \mathrm{~cm}^{3} \cdot \mathrm{mol}^{-1} \cdot \mathrm{s}^{-1}
\end{array}
$$

Any of the three reactions shown below, can lead to formation of $N_{2}(A)$ from $N_{2}(B)$. $\mathrm{N}_{2}$ (A) can then directly dissociate $\mathrm{H}_{2} \mathrm{~S}$ through $\mathrm{R} 5$.

$$
\begin{array}{ll}
\mathrm{N}_{2}(\mathrm{~B})+\mathrm{N}_{2} \rightarrow \mathrm{N}_{2}(\mathrm{~A})+\mathrm{N}_{2} & \mathrm{k}=1.81 \times 10^{13} \mathrm{~cm}^{3} \cdot \mathrm{mol}^{-1} \cdot \mathrm{s}^{-1} \\
\mathrm{~N}_{2}(\mathrm{~B})+\mathrm{Ar} \rightarrow \mathrm{N}_{2}(\mathrm{~A})+\mathrm{Ar} & \mathrm{k}=9.63 \times 10^{11} \mathrm{~cm}^{3} \cdot \mathrm{mol}^{-1} \cdot \mathrm{s}^{-1} \\
\mathrm{~N}_{2}(\mathrm{~B}) \rightarrow \mathrm{N}_{2}(\mathrm{~A})+\mathrm{h} v & \mathrm{k}=2.00 \times 10^{5} \mathrm{~s}^{-1}
\end{array}
$$


Thus, in $\mathrm{H}_{2} \mathrm{~S}-\mathrm{Ar}-\mathrm{N}_{2}$ mixtures, in addition to $\mathrm{N}_{2}(\mathrm{~A})$ formation by electron collision with $\mathrm{N}_{2}$ (R5) as in the $\mathrm{H}_{2} \mathrm{~S}-\mathrm{N}_{2}$ mixtures, there is a parallel route (R10-R15) to form $\mathrm{N}_{2}(\mathrm{~A})$. $\mathrm{N}_{2}(\mathrm{~A})$ and $\operatorname{Ar}\left({ }^{3} \mathrm{P}_{2}\right)$ are responsible for $\mathrm{H}_{2} \mathrm{~S}$ dissociation through reactions $\mathrm{R} 2$ and $\mathrm{R} 9$. This increase in $\mathrm{N}_{2}(\mathrm{~A})$ production is the probable reason for the increase in $\mathrm{H}_{2} \mathrm{~S}$ conversion in $\mathrm{H}_{2} \mathrm{~S}-\mathrm{Ar}-\mathrm{N}_{2}$ mixtures compared to that in $\mathrm{H}_{2} \mathrm{~S}-\mathrm{Ar}$ or $\mathrm{H}_{2} \mathrm{~S}-\mathrm{N}_{2}$ mixtures.

\subsection{Sulfur formation}

Sulfur is a product of direct decomposition of $\mathrm{H}_{2} \mathrm{~S}$. Initially, atomic sulfur is formed in high temperature areas of the discharge and then it dimerizes, forms clusters, and condenses in the low temperature zone on the discharge periphery (Fridman and Kennedy, 2004a). $\mathrm{S}$ and $\mathrm{S}_{2}$ have been reported in gas discharges (Elbanowski, 1969; Meyer, 1976). Formation of sulfur clusters $\left(S_{4}, S_{6}\right.$ and $\left.S_{8}\right)$ have also been reported during the microwave decomposition of $\mathrm{H}_{2} \mathrm{~S}$ (Fridman and Kennedy, 2004a). However, in the equilibrium vapor, below $400 \mathrm{~K}$ (close to our reactor temperature), $\mathrm{S}_{8}$ accounts for over 90 mol\% of the vapor, while $S_{6}$ and $S_{7}$ make up the rest (Meyer, 1976). The sulfur formed in the vapor phase in our reactor condenses as a grayish (sometimes grayishyellow) deposit. All sulfur allotropes with ring structures are yellow, while the sulfur chains are dark colored (Meyer, 1976). An X-ray diffraction study of the deposit shows the presence of orthorhombic- $\alpha$ sulfur, indicating that the sulfur formed in our reactor is a mixture of orthorhombic- $\alpha$ and other allotropes.

\section{Conclusions}

A novel reactor design, wire-in-tube configuration with view-ports, allowed visual observation of the corona all along the length of the reactor. The $\mathrm{H}_{2} \mathrm{~S}$ conversion 
and energy efficiency of $\mathrm{H}_{2} \mathrm{~S}$ decomposition in the pulsed corona discharge reactor varied greatly at a constant power. Low charge voltage, high pulse frequency, and low pulse forming capacitance operation produce the highest energy efficiency for $\mathrm{H}_{2} \mathrm{~S}$ conversion at constant power. Low charge voltage and high pulse frequency operation apparently does not produce inefficient secondary streamers, compared to high charge voltage and low pulse frequency conditions. Low pulse forming capacitance operation is closer to the optimum energy transfer condition, which allows better transfer of energy to the reactor and improves $\mathrm{H}_{2} \mathrm{~S}$ conversion and energy efficiency. The trend of increasing energy efficiency as the capacitance ratio approaches the optimum energy transfer ratio confirms these are the optimum energy transfer conditions for a high pressure, high concentration, and high flow rate system. Dilution of $\mathrm{H}_{2} \mathrm{~S}$-Ar feed mixtures with $\mathrm{N}_{2}$, increases the plasma volume within the reactor and may increase production of $\mathrm{N}_{2}(\mathrm{~A})$ species, which along with $\operatorname{Ar}\left({ }^{3} \mathrm{P}_{2}\right)$ appear responsible for $\mathrm{H}_{2} \mathrm{~S}$ dissociation. The lowest energy consumption for $\mathrm{H}_{2} \mathrm{~S}$ decomposition in a plasma reactor at non-vacuum pressures was obtained in an equimolar mixture of $\mathrm{Ar}$ and $\mathrm{N}_{2}$ at the lowest value of pulse forming capacitance. $\mathrm{H}_{2} \mathrm{~S}$ decomposition in an equimolar mixture of $\mathrm{Ar}$ and $\mathrm{N}_{2}$, combined with improved reactor geometry to optimize pulse forming capacitance for maximum energy transfer, should increase energy efficiency further.

\section{Acknowledgements}

This work was supported by the Department of Energy (DE-FC26-03NT41963), the Idaho National Laboratory Directed Research and Development (Battelle 47698), the 
University of Wyoming Research Office, and the University of Wyoming School of Energy Resources. The authors gratefully acknowledge experimental assistance provided by Mr. R. Borgialli. 


\section{Figure Captions}

Figure 1. Experimental setup

Figure 2. Reactor electrical circuit diagram

Figure 3. Corona discharge as seen through a viewport

Figure 4. Conversion of $\mathrm{H}_{2} \mathrm{~S}$ as a function of charge voltage and capacitance. (a) $8 \%$ $\mathrm{H}_{2} \mathrm{~S}-92 \%$ Ar (b) $12 \% \mathrm{H}_{2} \mathrm{~S}-88 \%$ Ar

Data: $720 \mathrm{pF}(\boldsymbol{\square}), 1440 \mathrm{pF}(\boldsymbol{\Delta}), 2160 \mathrm{pF}(\times), 2880 \mathrm{pF}(\bullet)$

Figure 5. Energy consumption per $\mathrm{H}_{2} \mathrm{~S}$ molecule converted as a function of charge voltage and capacitance. (a) $8 \% \mathrm{H}_{2} \mathrm{~S}-92 \%$ Ar (b) $12 \% \mathrm{H}_{2} \mathrm{~S}-88 \% \mathrm{Ar}$ Data: 720 pF (घ), $1440 \mathrm{pF}(\boldsymbol{\Delta}), 2160 \mathrm{pF}(\times), 2880 \mathrm{pF}(\bullet)$

Figure 6. Energy consumption per $\mathrm{H}_{2} \mathrm{~S}$ molecule converted as a function of capacitance ratio at a charge voltage of $17 \mathrm{kV}$. Data: $8 \% \mathrm{H}_{2} \mathrm{~S}-92 \% \operatorname{Ar}(\boldsymbol{\square}), 12 \% \mathrm{H}_{2} \mathrm{~S}-88 \% \operatorname{Ar}(\boldsymbol{\Delta})$

Figure 7. $\mathrm{H}_{2} \mathrm{~S}$ conversion in Ar- $\mathbf{N}_{2}$ mixture as balance gas Data: $100 \mathrm{~W}(\diamond), 80 \mathrm{~W}(\mathbf{\bullet}), 60 \mathrm{~W}(\boldsymbol{\Delta})$

Figure 8. Energy consumption for $\mathrm{H}_{2} \mathrm{~S}$ decomposition in $\mathrm{Ar}-\mathrm{N}_{2}$ mixture as balance gas

Data: $100 \mathrm{~W}(\bullet), 80 \mathrm{~W}(\boldsymbol{\bullet}), 60 \mathrm{~W}(\boldsymbol{\Delta})$ 


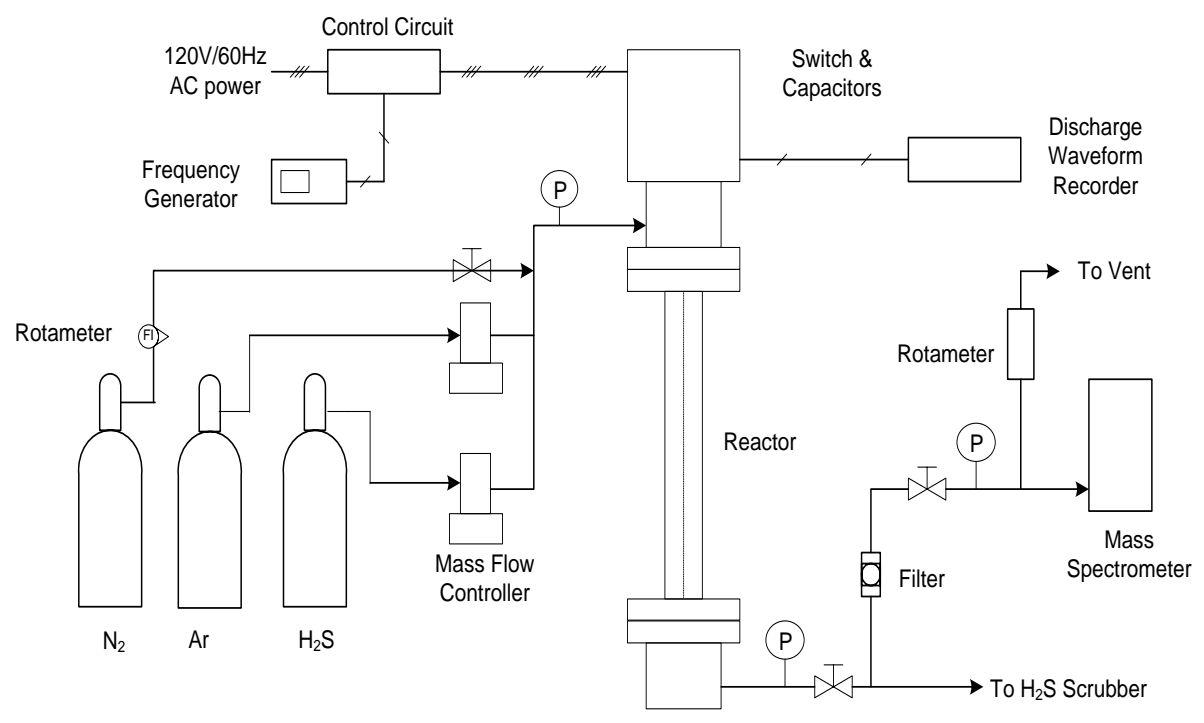

Figure 1. Experimental setup 


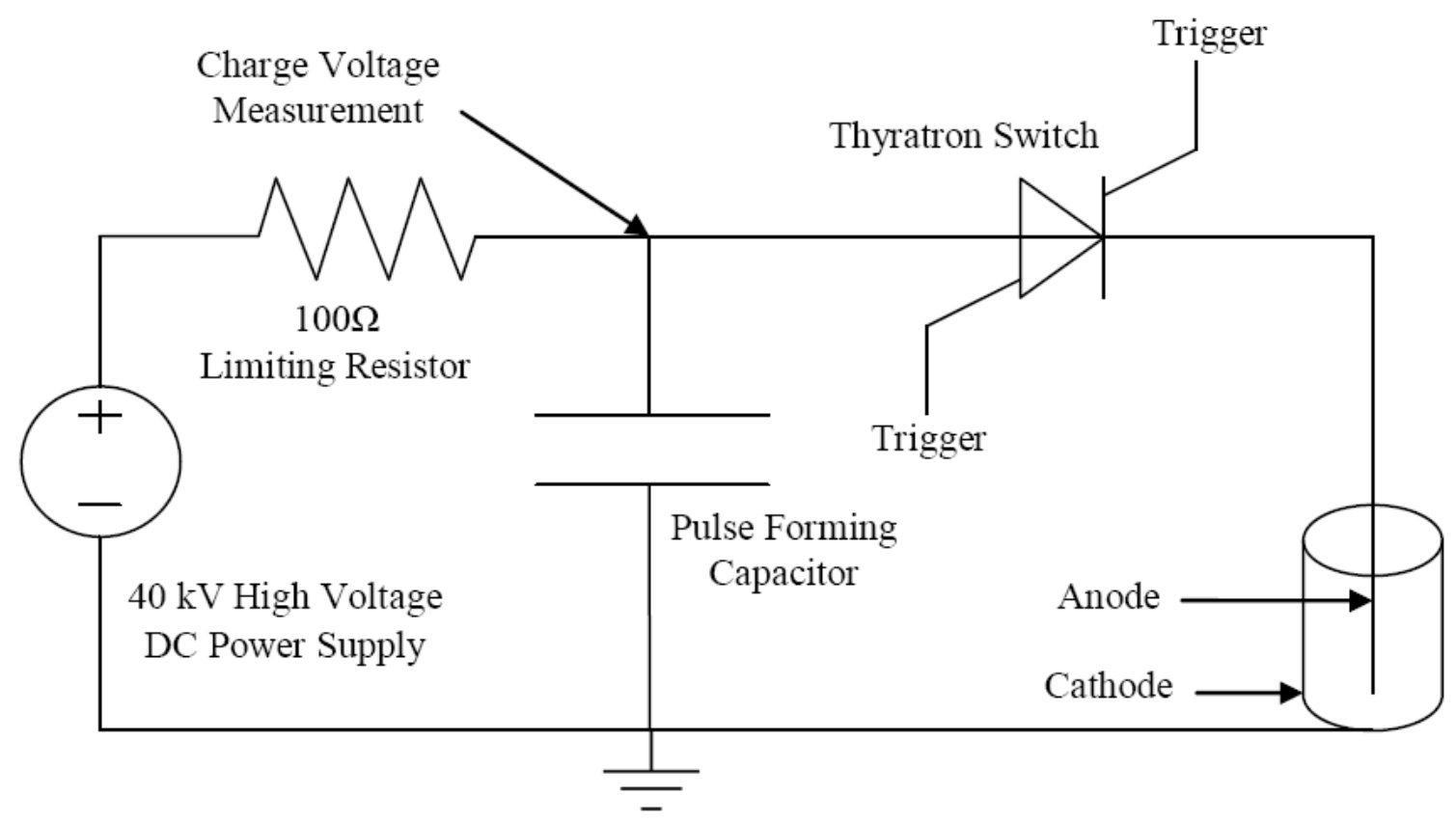

Figure 2. Reactor electrical circuit diagram 


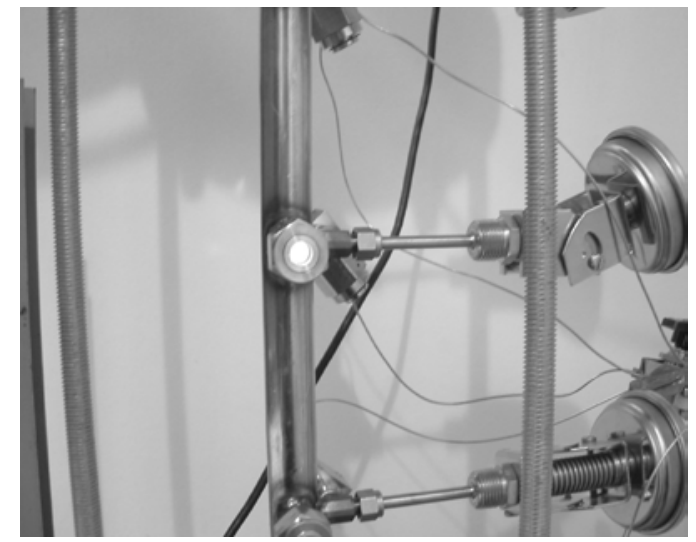

Figure 3. Corona discharge as seen through a viewport 


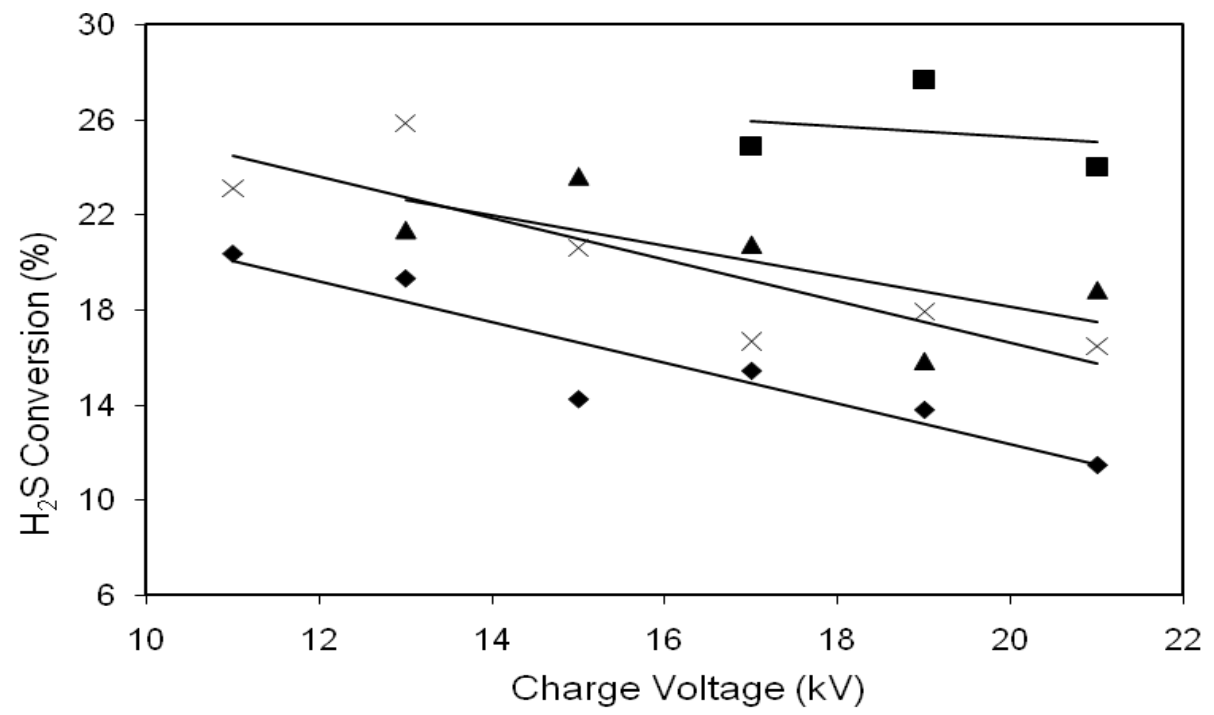

(a) $8 \% \mathrm{H}_{2} \mathrm{~S}-92 \% \mathrm{Ar}$

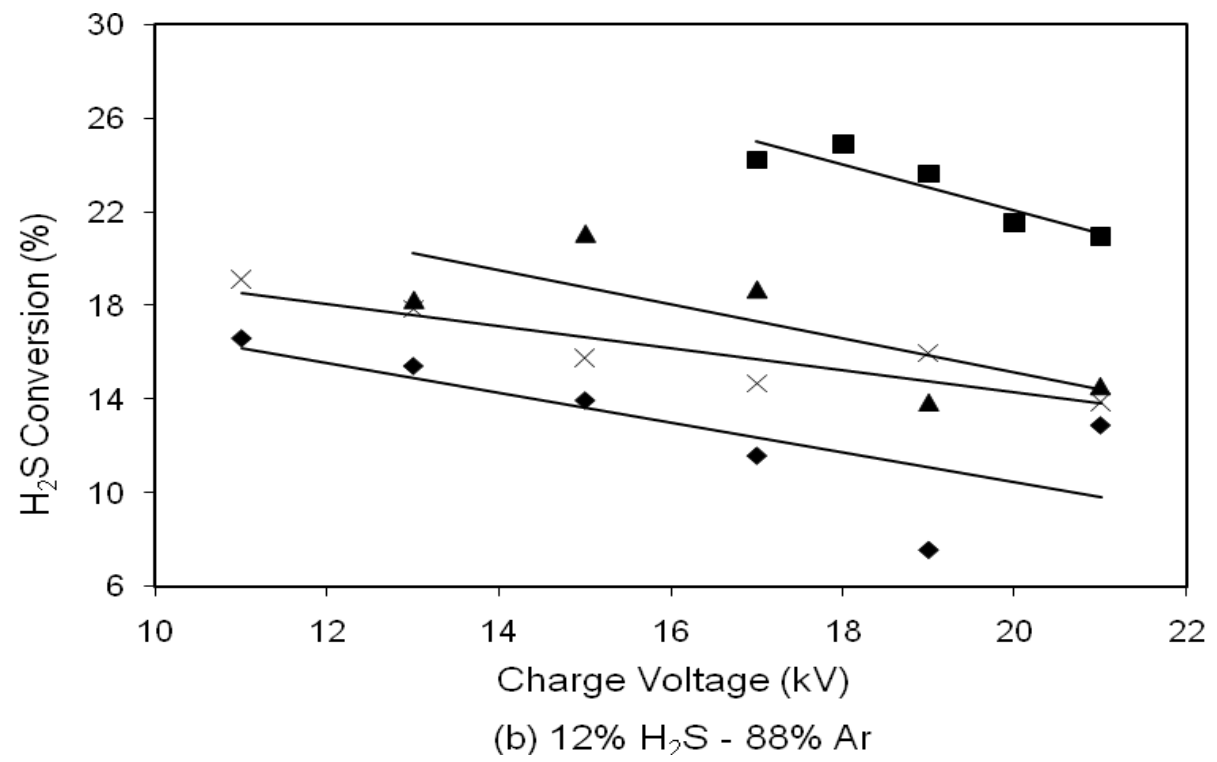

Figure 4. Conversion of $\mathrm{H}_{2} \mathrm{~S}$ as a function of charge voltage and capacitance.

(a) $8 \% \mathrm{H}_{2} \mathrm{~S}-92 \% \mathrm{Ar}$ (b) $12 \% \mathrm{H}_{2} \mathrm{~S}-88 \% \mathrm{Ar}$

Data: $720 \mathrm{pF}(\mathbf{\bullet}), 1440 \mathrm{pF}(\boldsymbol{\Delta}), 2160 \mathrm{pF}(\times), 2880 \mathrm{pF}(\bullet)$ 


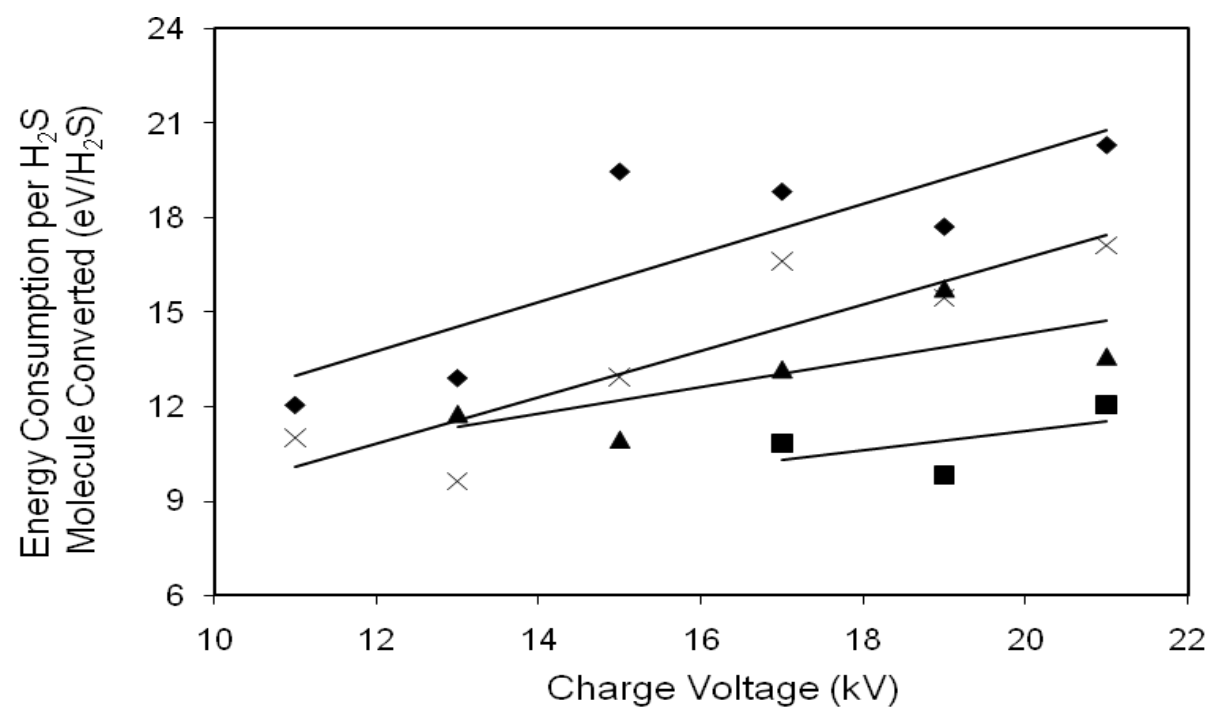

(a) $8 \% \mathrm{H}_{2} \mathrm{~S}$ in $\mathrm{Ar}$

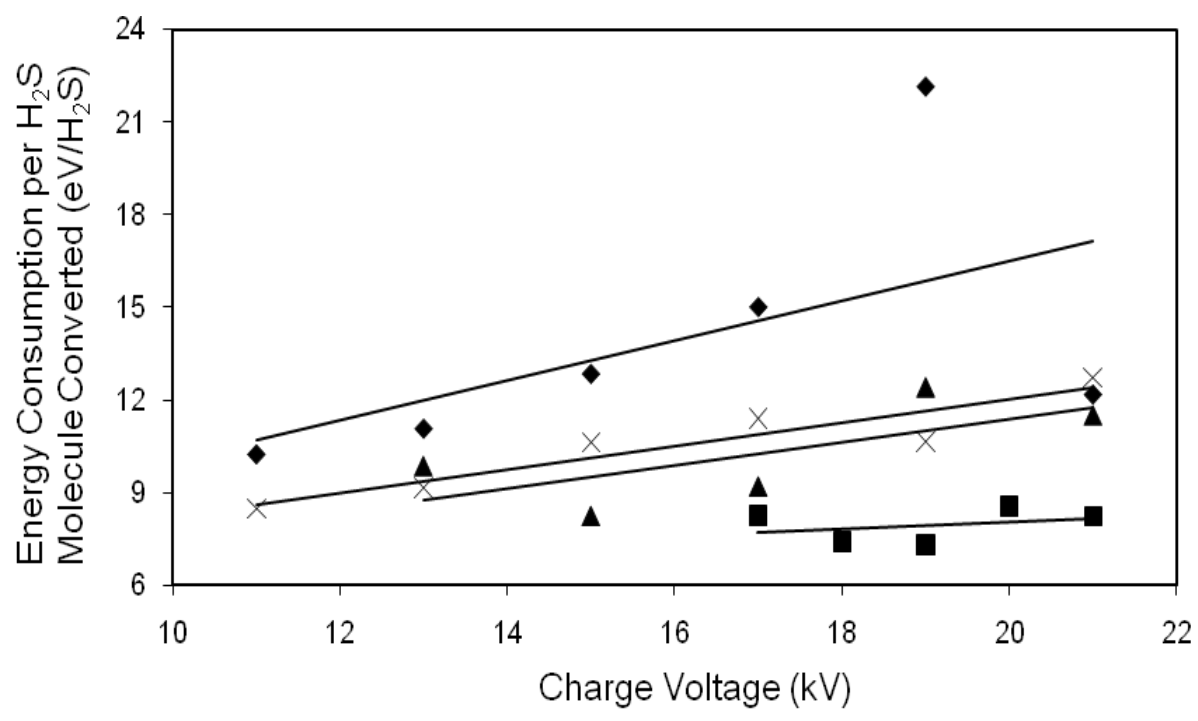

(b) $12 \% \mathrm{H}_{2} \mathrm{~S}-88 \% \mathrm{Ar}$

Figure 5. Energy consumption per $\mathrm{H}_{2} \mathrm{~S}$ molecule converted as a function of charge voltage and capacitance. (a) $8 \% \mathrm{H}_{2} \mathrm{~S}-92 \% \mathrm{Ar}$ (b) $12 \% \mathrm{H}_{2} \mathrm{~S}-88 \% \mathrm{Ar}$

Data: $720 \mathrm{pF}(\mathbf{\bullet}), 1440 \mathrm{pF}(\mathbf{\Lambda}), 2160 \mathrm{pF}(\times), 2880 \mathrm{pF}(\bullet)$ 


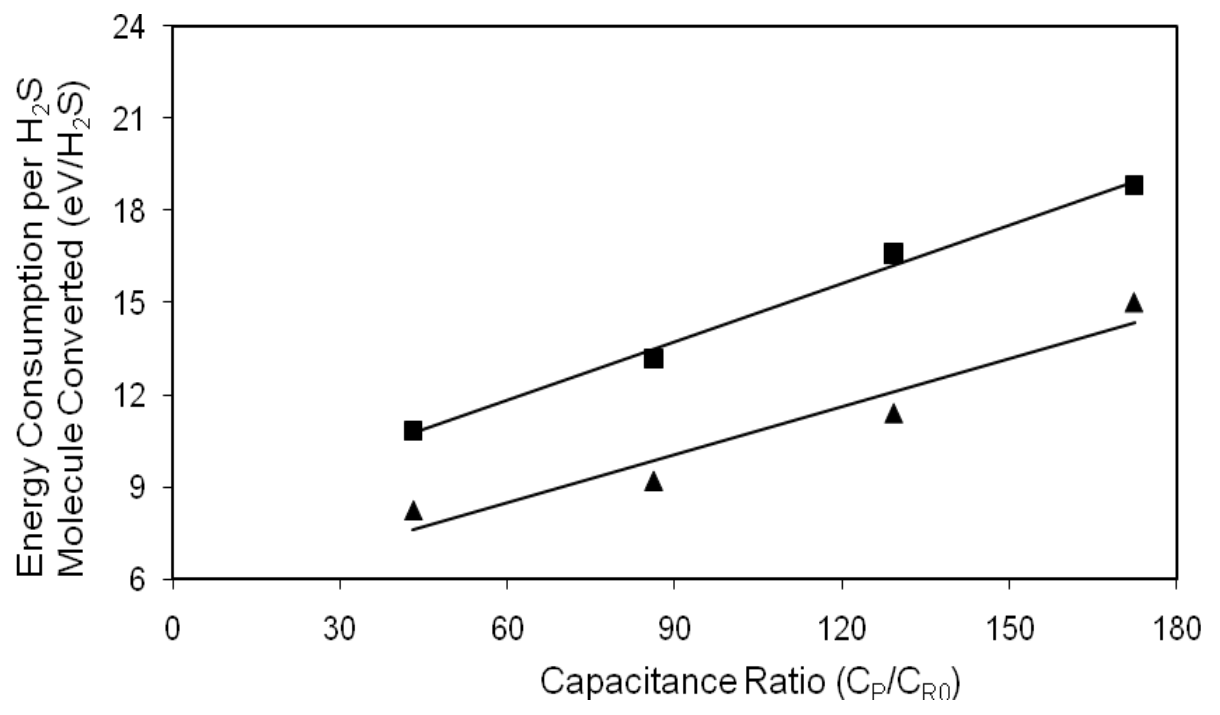

Figure 6. Energy consumption per $\mathrm{H}_{2} \mathrm{~S}$ molecule converted as a function of capacitance ratio at a charge voltage of $17 \mathrm{kV}$.

Data: $8 \% \mathrm{H}_{2} \mathrm{~S}-92 \% \operatorname{Ar}(\boldsymbol{\square}), 12 \% \mathrm{H}_{2} \mathrm{~S}-88 \% \operatorname{Ar}(\boldsymbol{\Delta})$ 


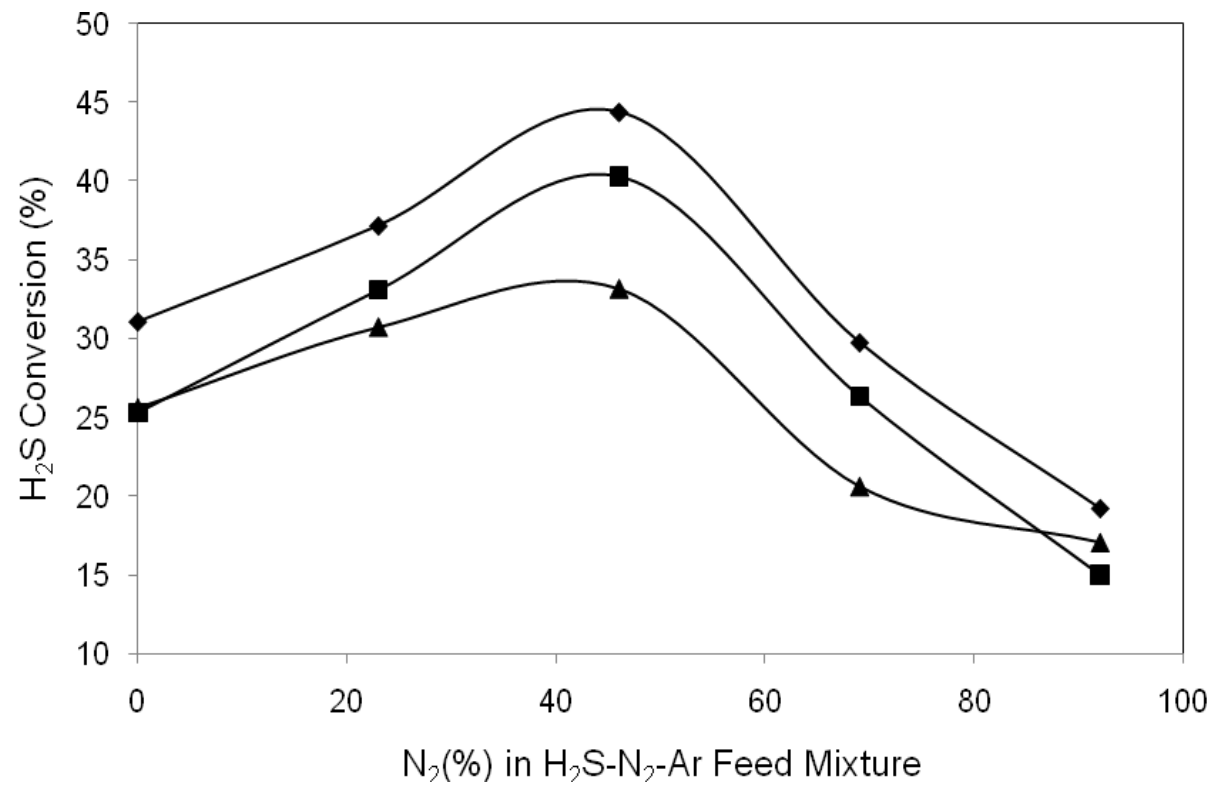

Figure 7. $\mathrm{H}_{2} \mathrm{~S}$ conversion in Ar- $\mathrm{N}_{2}$ mixture as balance gas

Data: $100 \mathrm{~W}(\bullet), 80 \mathrm{~W}(\bullet), 60 \mathrm{~W}(\mathbf{\Delta})$ 


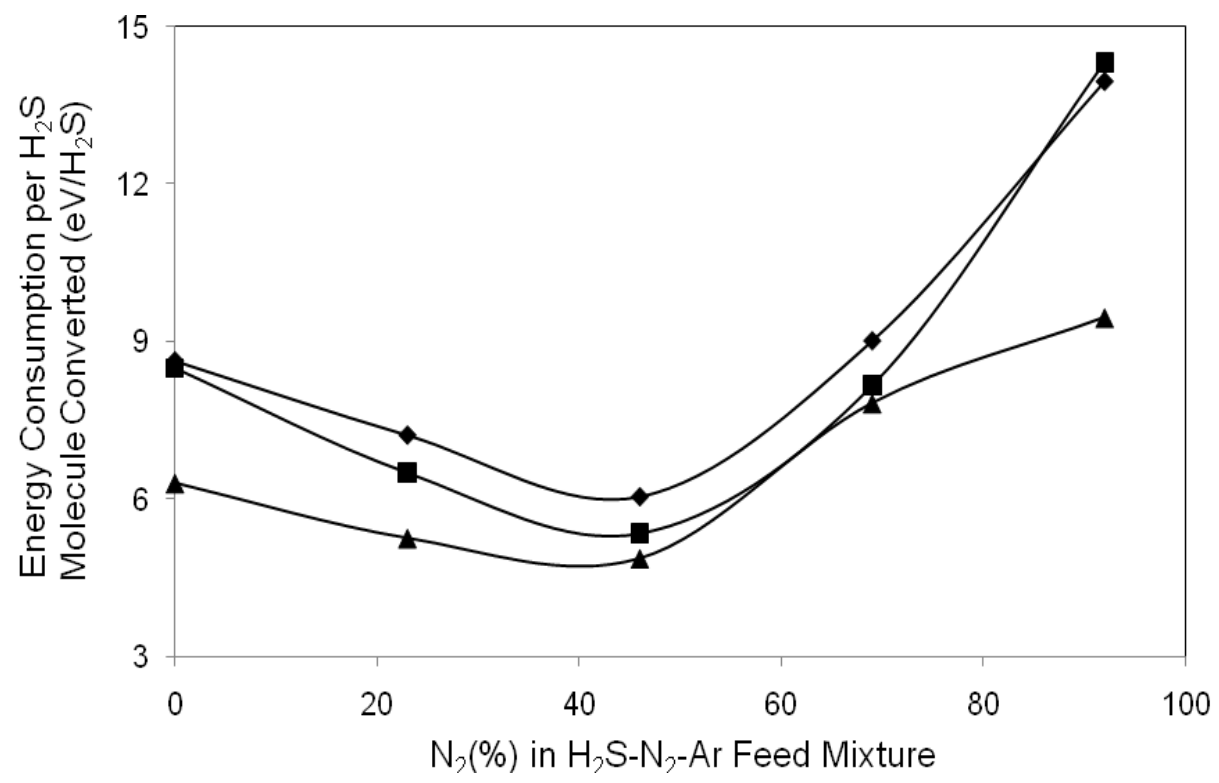

Figure 8. Energy consumption for $\mathrm{H}_{2} \mathrm{~S}$ decomposition in Ar- $\mathrm{N}_{2}$ mixture as balance gas Data: $100 \mathrm{~W}(\bullet), 80 \mathrm{~W}(\mathbf{\bullet}), 60 \mathrm{~W}(\mathbf{\Delta})$ 


\section{Table Captions}

Table 1. Molar composition of feed gas mixtures for experiments involving nitrogen

Table 2. Electrical parameters for constant power experiments at $100 \mathrm{~W}$

Table 3. Electrical parameters for experiments involving nitrogen

Table 4. Electron collision with $\mathrm{H}_{2} \mathrm{~S}$ in primary and secondary streamers

(* denotes an excited state as proposed by (Rao and Srivastava, 1993))

Table 5. Decrease in energy consumption with decrease in capacitance ratio (Representative data, at $17 \mathrm{kV}$ ) 


\begin{tabular}{|cccc|}
\hline Gas Mixture \# & $\mathrm{H}_{2} \mathrm{~S}(\%)$ & $\mathrm{Ar}(\%)$ & $\mathrm{N}_{2}(\%)$ \\
\hline 1 & 8 & 92 & 0 \\
\hline 2 & 8 & 69 & 23 \\
\hline 3 & 8 & 46 & 46 \\
\hline 4 & 8 & 23 & 69 \\
\hline 5 & 8 & 0 & 92 \\
\hline
\end{tabular}

Table 1. Molar composition of feed gas mixtures for experiments involving nitrogen 


\begin{tabular}{|ccccccc|}
\hline \multirow{2}{*}{ Pulse forming capacitance $\left(\mathrm{C}_{\mathrm{P}}, \mathrm{pF}\right)$} & \multicolumn{5}{c|}{ Charge voltage $(\mathrm{V}, \mathrm{kV})$} \\
\cline { 2 - 7 } & \multicolumn{5}{c|}{ Pulse frequency $(\mathrm{f}, \mathrm{Hz})$} \\
\hline \multirow{2}{*}{720} & 11 & 13 & 15 & 17 & 19 & 21 \\
\cline { 2 - 7 } & - & - & - & 961 & 769 & 630 \\
\hline \multirow{2}{*}{1440} & 11 & 13 & 15 & 17 & 19 & 21 \\
& - & 822 & 618 & 481 & 385 & 315 \\
\hline \multirow{2}{*}{2160} & 11 & 13 & 15 & 17 & 19 & 21 \\
\cline { 2 - 7 } & 765 & 548 & 412 & 320 & 256 & 210 \\
\hline \multirow{2}{*}{2880} & 11 & 13 & 15 & 17 & 19 & 21 \\
\cline { 2 - 6 } & 574 & 411 & 309 & 240 & 192 & 157 \\
\hline
\end{tabular}

Table 2. Electrical parameters for constant power experiments at $100 \mathrm{~W}$ 


\begin{tabular}{|cccc|}
\hline Power $(\mathrm{P}, \mathrm{W})$ & 60 & 80 & 100 \\
\hline Pulse forming capacitance $\left(\mathrm{C}_{\mathrm{P}}, \mathrm{pF}\right)$ & 720 & 720 & 720 \\
\hline Charge voltage $(\mathrm{V}, \mathrm{kV})$ & 13 & 15 & 17 \\
\hline Pulse frequency (f, Hz) & 986 & 988 & 961 \\
\hline
\end{tabular}

Table 3. Electrical parameters for experiments involving nitrogen 


\begin{tabular}{|cc|}
\hline Primary streamer processes & Approximate cross section $\left(10^{-23} \mathrm{~m}^{2}\right)$ \\
\hline $\mathrm{H}_{2} \mathrm{~S}+\mathrm{e}(\sim 10 \mathrm{eV}) \rightarrow \mathrm{H}^{*}+\mathrm{HS}^{-}$ & 0.15 \\
\hline $\mathrm{H}_{2} \mathrm{~S}+\mathrm{e}(\sim 10 \mathrm{eV}) \rightarrow 2 \mathrm{H}^{*}\left(\right.$ or $\left._{2}{ }^{*}\right)+\mathrm{S}^{-}$ & 3.8 \\
\hline $\mathrm{H}_{2} \mathrm{~S}+\mathrm{e}(\sim 10 \mathrm{eV}) \rightarrow \mathrm{H}_{2} \mathrm{~S}^{+}+2 \mathrm{e}$ & 100 \\
\hline $\mathrm{H}_{2} \mathrm{~S}+\mathrm{e}(\sim 10.45 \mathrm{eV}) \rightarrow \mathrm{H}_{2} \mathrm{~S}^{+}+2 \mathrm{e}$ & 758 \\
\hline $\mathrm{Secondary}$ streamer processes & Approximate cross section $\left(10^{-23} \mathrm{~m}^{2}\right)$ \\
\hline $\mathrm{H}_{2} \mathrm{~S}+\mathrm{e}(2.28 \mathrm{eV}) \rightarrow \mathrm{H}^{2} \mathrm{HS}^{-}$ & 18 \\
\hline $\mathrm{H}_{2} \mathrm{~S}+\mathrm{e}(2.5 \mathrm{eV}) \rightarrow \mathrm{H}_{2}+\mathrm{S}^{-}$ & 3.3 \\
\hline
\end{tabular}

Table 4. Electron collision with $\mathrm{H}_{2} \mathrm{~S}$ in primary and secondary streamers

(* denotes an excited state as proposed by (Rao and Srivastava, 1993)) 


\begin{tabular}{|ccccc|}
\hline $\begin{array}{c}\text { Pulse forming capacitance } \\
\text { (C, } \mathrm{pF} \text { ) }\end{array}$ & 720 & 1440 & 2160 & 2880 \\
\hline $\begin{array}{c}\text { Capacitance ratio } \\
\left(\mathrm{C}_{\mathrm{p}} / \mathrm{C}_{\mathrm{R} 0}\right)\end{array}$ & 45 & 90 & 135 & 180 \\
\hline $\begin{array}{c}\text { Energy consumption in } 8 \% \mathrm{H}_{2} \mathrm{~S}-92 \% \text { Ar mixture } \\
\text { (E, eV/ } \mathrm{H}_{2} \mathrm{~S} \text { molecule converted) }\end{array}$ & 10.8 & 13.2 & 16.6 & 18.8 \\
\hline $\begin{array}{c}\text { Energy consumption in } 12 \% \mathrm{H}_{2} \mathrm{~S}-88 \% \text { Ar mixture } \\
\left(\mathrm{E}, \mathrm{eV} / \mathrm{H}_{2} \mathrm{~S} \text { molecule converted) }\right.\end{array}$ & 8.2 & 9.2 & 11.4 & 15.0 \\
\hline
\end{tabular}

Table 5. Decrease in energy consumption with decrease in capacitance ratio (Representative data, at $17 \mathrm{kV}$ ) 


\section{References}

2002, Hydrogen Thyratrons Preamble, A1A-Hydrogen Thyratrons Preamble, E2V Technologies Limited, p. 1-21.

2004, Basic Research Needs for the Hydrogen Economy, The "Basic Research Needs" Workshop Series, Argonne National Laboratory.

2005, Today's Hydrogen Production Technology, Hydrogen \& Clean Fuels Research, Washington, D.C., Fossil Energy Office of Communications. http://www.fossil.energy.gov/programs/fuels/hydrogen/currenttechnology.html

2008, Chemical Profiles, The Innovation Group. http://www.the-innovation-group.com/ChemProfiles/Hydrogen.htm

Abolentsev, V. A., S. V. Korobtsev, D. D. Medvedev, B. V. Potapkin, V. D. Rusanov, A. A. Fridman, and V. L. Shiryaevskii, 1995, Pulsed wet discharge as an effective means of gas purification from H2S and organosulfur impurities: High Energy Chemistry, v. 29, p. 353-357.

Aleksandrov, E. N., V. Y. Basevich, and V. I. Vedeneev, 1994, Initial act of nitrogen atom interaction with H2 in gas-phase: Khimicheskaya Fizika, v. 13, p. 90-93.

Asisov, R. I., A. K. Vakar, A. F. Gutsol, V. K. Givotov, E. G. Krasheninnikov, M. F. Krotov, V. D. Rusanov, A. A. Fridman, and G. V. Sholin, 1985, Plasmachemical methods of energy carrier production: International Journal of Hydrogen Energy, v. 10, p. 475-477.

Averin, V. G., V. B. Potapkin, V. D. Rusanov, A. A. Fridman, and V. L. Shiryaevskii, 1996, Dissociation of hydrogen sulfide molecules in a pulsed electric discharge: High Energy Chemistry, v. 30, p. 125-127.

Bagautdinov, A. Z., V. K. Jivotov, J. I. Eremenko, I. A. Kalachev, A. I. Kozbagarov, E. I. Konstantinov, S. A. Musinov, K. I. Overchuk, V. D. Rusanon, and V. A. Zoller, 1998, Plasmachemical hydrogen production from natural gases containing hydrogen sulfide.: World Hydrogen Energy Conference, p. 683-689.

Bagautdinov, A. Z., V. K. Jivotov, J. I. Eremenko, I. A. Kalachev, S. A. Musinov, A. M. Pampushka, V. D. Rusanon, and V. A. Zoller, 1993a, Natural hydrogen sulfide (H2S) - source of hydrogen (plasma chemical dissociation): Frontier Science Series, v. 7, p. 123-125.

Bagautdinov, A. Z., V. K. Jivotov, J. I. Eremenko, I. A. Kalachev, S. A. Musinov, B. V. Potapkin, A. M. Pampushka, V. D. Rusanov, M. I. Strelkova, A. A. Fridman, and V. A. Zoller, 1995, Plasma chemical production of hydrogen from H2Scontaining gases in MCW discharge: International Journal of Hydrogen Energy, v. 20, p. 193-195.

Bagautdinov, A. Z., V. K. Zhivotov, I. A. Kalachev, S. A. Musinov, A. M. Pampushka, V. D. Rusanov, and V. A. Tsoller, 1993b, Investigations of the radial distributions of gas-flows in a high-power microwave-discharge: High Energy Chemistry, v. 27, p. 305-310.

Bagautdinov, A. Z., V. K. Zhivotov, S. V. Musinov, A. M. Pampushka, V. D. Rusanov, V. A. Tsoller, and P. Y. Epp, 1992, Physical and chemical processes during the dissociation of H2S-CO2 mixtures in microwave discharges: High Energy Chemistry, v. 26, p. 55-61. 
Bingyan, D., L. Jie, W. Yan, and L. Guofeng, 2005, Experimental study of streamer energy in pulsed corona discharge (Brief communication): Japanese Journal of Applied Physics, v. 44, p. 1959-1960.

Christophorou, L. G., H. Rodrigo, E. Marode, and F. Bastien, 1987, Isotopic dependencies of the dielectric strength of gases - new observations, classification, and possible origins: Journal of Physics D-Applied Physics, v. 20, p. 1031-1038.

Cohen, N., and K. R. Westberg, 1991, Chemical kinetic data sheets for high-temperature reactions. Part II: Journal of Physical and Chemical Reference Data, v. 20, p. 1211-1311.

Cox, B. G., P. F. Clarke, and B. B. Pruden, 1998, Economics of thermal dissociation of H2S to produce hydrogen: International Journal of Hydrogen Energy, v. 23, p. 531-544.

Dalaine, V., J. M. Cormier, and P. Lefaucheux, 1998a, A gliding discharge applied to H2S destruction: Journal of Applied Physics, v. 83, p. 2435-2441.

Dalaine, V., J. M. Cormier, S. Pellerin, and P. Lefaucheux, 1998b, H2S destruction in 50 $\mathrm{Hz}$ and $25 \mathrm{kHz}$ gliding arc reactors: Journal of Applied Physics, v. 84, p. 12151221.

Elbanowski, M., 1969, Flash photolysis of sulfur vapor: Roczniki Chemii, v. 43, p. 18831890.

Fridman, A., and L. A. Kennedy, 2004a, Plasma Physics and Engineering: New York, Taylor \& Francis, 771 p.

Fridman, A., and L. A. Kennedy, 2004b, Plasma Physics and Engineering: New York, Taylor \& Francis, $42 \mathrm{p}$.

Fridman, A., and L. A. Kennedy, 2004c, Plasma Physics and Engineering: New York, Taylor \& Francis, 99 p.

Fridman, A., and L. A. Kennedy, 2004d, Plasma Physics and Engineering: New York, Taylor \& Francis, 75 p.

Gundel, L. A., D. W. Setser, M. A. A. Clyne, J. A. Coxon, and W. Nip, 1976, Rate constants for specific product channels from metastable $\operatorname{Ar}(\mathrm{P}-3(2,0)$ reactions and spectrometer calibration in vacuum ultraviolet: Journal of Chemical Physics, v. 64, p. 4390-4410.

Haas, L. A., and S. E. Khalafalla, 1973, Decomposition of hydrogen sulfide in an electrical discharge, Report of Investigations, Washington, D.C., Twin Cities Metallurgy Research Center, p. 1-21.

Helfritch, D. J., 1993, Pulsed corona discharge for hydrogen-sulfide decomposition: Ieee Transactions on Industry Applications, v. 29, p. 882-886.

Herron, J. T., 1999, Evaluated chemical kinetics data for reactions of N(D-2), N(P-2), and N2(A(3)Sigma $(+)(u))$ in the gas phase: Journal of Physical and Chemical Reference Data, v. 28, p. 1453-1483.

Huang, C. P., and A. T-Raissi, 2008, Liquid hydrogen production via hydrogen sulfide methane reformation: Journal of Power Sources, v. 175, p. 464-472.

Kossyi, I. A., A. Y. Kostinsky, A. A. Matveyev, and V. P. Silakov, 1992, Kinetic scheme of the non-equilibrium discharge in nitrogen-oxygen mixtures: Plasma Sources Science and Technology, v. 1, p. 207-220.

Lide, D. R., Ed., 2003, CRC Handbook of Chemistry and Physics: CRC Handbook of Chemistry \& Physics: Boca Raton, CRC Press LLC, 9-66 p. 
Ma, H., P. L. Chen, and R. Ruan, 2001, H2S and NH3 removal by silent discharge plasma and ozone combo system: Plasma Chemistry and Plasma Processing, v. 21, p. 611-624.

Meyer, B., 1976, Elemental sulfur: Chemical Reviews, v. 76, p. 367-388.

Mok, Y. S., 2000, Efficient energy delivery condition from pulse generation circuit to corona discharge reactor: Plasma Chemistry and Plasma Processing, v. 20, p. 353364.

Rao, M. V. V. S., and S. K. Srivastava, 1993, Electron impact ionization and attachment cross sections for H2S: Journal of Geophysical Research, v. 98, p. 13137-13145.

Ruan, R. R., W. Han, A. Ning, P. L. Chen, P. R. Goodrich, and R. Zhang, 1999, Treatment of odorous and hazardous gases using non-thermal plasma: Journal of Advanced Oxidation Technologies, v. 4, p. 328-332.

Shin, D. N., C. W. Park, and J. W. Hahn, 2000, Detection of OH(A(2)Sigma(+)) and $\mathrm{O}(\mathrm{D}-1)$ emission spectrum generated in a pulsed corona plasma: Bulletin of the Korean Chemical Society, v. 21, p. 228-232.

Smith, J. M., and H. C. Van Ness, 1987, Introduction to Chemical Engineering Thermodynamics: McGraw-Hill Chemical Engineering Series: Singapore, McGraw-Hill Book Company, $121 \mathrm{p}$.

Szmytkowski, C., P. Mozejko, and A. Krzysztofowicz, 2003, Measurements of absolute total cross sections for electron scattering from triatomic polar molecules: SO2 and H2S: Radiation Physics and Chemistry, v. 68, p. 307-311.

Traus, I., and H. Suhr, 1992, Hydrogen-sulfide dissociation in ozonizer discharges and operation of ozonizers at elevated-temperatures: Plasma Chemistry and Plasma Processing, v. 12, p. 275-285.

Traus, I., H. Suhr, J. E. Harry, and D. R. Evans, 1993, Application of a rotating highpressure glow-discharge for the dissociation of hydrogen-sulfide: Plasma Chemistry and Plasma Processing, v. 13, p. 77-91.

Uhm, H. S., and W. M. Lee, 1997, An analytical theory of corona discharge plasmas: Physics of Plasmas, v. 4, p. 3117-3128.

Velazco, J. E., J. H. Kolts, and D. W. Setser, 1978, Rate constants and quenching mechanisms for metastable states of argon, krypton, and xenon: Journal of Chemical Physics, v. 69, p. 4357-4373.

Watson, J. T., 1997, Introduction to Mass Spectrometry: Philadelphia, Lippincott-Raven.

Winands, G. J. J., Z. Liu, A. J. M. Pemen, E. J. M. van Heesch, K. Yan, and E. M. van Veldhuizen, 2006, Temporal development and chemical efficiency of positive streamers in a large scale wire-plate reactor as a function of voltage waveform parameters: Journal of Physics D-Applied Physics, v. 39, p. 3010-3017.

Wiseman, N., and W. J. M. Douglas, 1972, Oxidation of hydrogen sulfide in a corona discharge: A. I. Ch. E. Symposium Series, v. 68, p. 297-301.

Yan, K. P., H. X. Hui, M. Cui, J. S. Miao, X. L. Wu, C. G. Bao, and R. N. Li, 1998, Corona induced non-thermal plasmas: Fundamental study and industrial applications: Journal of Electrostatics, v. 44, p. 17-39.

Yao, S. L., A. Nakayama, and E. Suzuki, 2001, Methane conversion using a highfrequency pulsed plasma: Discharge features: A.I.Ch.E. Journal, v. 47, p. 419426. 
Zhao, G. B., M. D. Argyle, and M. Rodosz, 2006a, Effect of CO on NO and N2O conversions in nonthermal argon plasma: Journal of Applied Physics, v. 99.

Zhao, G. B., S. B. J. Garikipati, X. D. Hu, M. D. Argyle, and M. Radosz, 2005a, The effect of gas pressure on NO conversion energy efficiency in nonthermal nitrogen plasma: Chemical Engineering Science, v. 60, p. 1927-1937.

Zhao, G. B., S. V. B. Garikipati, X. D. Hu, M. D. Argyle, and M. Radosz, 2005b, Effect of oxygen on nonthermal plasma reactions of nitrogen oxides in nitrogen:

A.I.Ch.E. Journal, v. 51, p. 1800-1812.

Zhao, G. B., X. D. Hu, M. D. Argyle, and M. Radosz, 2004, N atom radicals and N2(A(3)Sigma $(+)(\mathrm{u}))$ found to be responsible for nitrogen oxides conversion in nonthermal nitrogen plasma: Industrial \& Engineering Chemistry Research, v. 43, p. 5077-5088.

Zhao, G. B., X. D. Hu, M. D. Argyle, and M. Radosz, 2005c, Effect of CO2 on nonthermal-plasma reactions of nitrogen oxides in N-2. Part II: Percent-level concentrations: Industrial \& Engineering Chemistry Research, v. 44, p. 39353946.

Zhao, G. B., S. John, J. J. Zhang, J. C. Hamann, S. S. Muknahallipatna, S. Legowski, J. F. Ackerman, and M. D. Argyle, 2007, Production of hydrogen and sulfur from hydrogen sulfide in a nonthermal-plasma pulsed corona discharge reactor: Chemical Engineering Science, v. 62, p. 2216-2227.

Zhao, G. B., S. John, J. J. Zhang, L. N. Wang, S. Muknahallipatna, J. C. Hamann, J. F. Ackerman, M. D. Argyle, and O. A. Plumb, 2006b, Methane conversion in pulsed corona discharge reactors: Chemical Engineering Journal, v. 125, p. 67-79. 